\title{
A Control Scheme without Sensors at the PV Source for Cost and Size Reduction in Two-Stage Grid Connected Inverters
}

\author{
Raúl González-Medina *D, Marian Liberos, Silvia Marzal, Emilio Figueres and Gabriel Garcerá $\mathbb{D}$ \\ Grupo de Sistemas Electrónicos Industriales del Departamento de Ingeniería Electrónica, Universitat Politècnica \\ de València, Camino de Vera s/n, 46022 Valencia, Spain \\ * Correspondence: raugonme@upv.es; Tel.: +34-963-879-606
}

Received: 21 June 2019; Accepted: 23 July 2019; Published: 1 August 2019

check for updates

\begin{abstract}
In order to reduce the cost of PV facilities, the market requires low cost and highly reliable $\mathrm{PV}$ inverters, which must comply with several regulations. Some research has focused on decreasing the distortion of the current injected into the grid, reducing the size of the DC-link capacitors and removing sensors, while keeping a good performance of the maximum power point tracking (MPPT) algorithms. Although those objectives are different, all of them are linked to the inverter DC-link voltage control loop. Both the reduction of the DC-link capacitance and the use of sensorless MPPT algorithms require a voltage control loop faster than that of conventional implementations in order to perform properly, but the distortion of the current injected into the grid might rise as a result. This research studies a complete solution for two-stage grid-connected PV inverters, based on the features of second-order generalized integrators. The experimental tests show that the proposed implementation has a performance similar to that of the conventional control of two-stage PV inverters but at a much lower cost.
\end{abstract}

Keywords: photovoltaics; two-stage grid-connected PV inverters; reduced DC-link; sensorless MPPT

\section{Introduction}

In order to reduce the installation and maintenance costs, the photovoltaic (PV) market requires low cost and reliable systems. Moreover, grid-connected PV inverters must comply with several electromagnetic compatibility (EMC) regulations, some of which limit the distortion of the current injected into the grid (THDi), like IEC EN61000 and IEEE519 [1-4]. Maximum power point tracking (MPPT) algorithms are implemented to optimize the performance of PV systems [5-9]. Conventional MPPT algorithms use current and voltage sensors to calculate the power extracted from the PV source. Several investigations have focused on reducing the number of sensors in PV inverters when implementing MPPT algorithms [10-13], which has a positive impact on cost reduction.

One possible solution to achieve both a good maximum point tracking (MPPT) performance and a reduced THDi is the use of two-stage grid-connected PV inverters, based on a DC-DC converter connected to the PV source, followed by a grid-connected inverter [14-16]. This paper focused on this kind of topologies.

There is a trend to reduce the required capacitance at the DC-link between the DC-DC converter and the inverter stage, which allows replacing electrolytic capacitors by film capacitors, which are more durable [17-22]. Two major effects of the DC-link capacitance reduction are the increase of the voltage ripple at the capacitors and higher transient variations of that voltage under dynamic operation point changes of the inverter. These variations must be bound for the proper operation of the inverter.

In this research, the implementation of control structures based on second-order generalized integrators (SOGI) [23-27] is proposed to support the DC-link capacitance reduction of two-stage 
grid-connected PV inverters with a small number of sensors. On the one hand, it will be shown that SOGIs can improve the dynamic response of the DC-link voltage. On the other hand, the frequency adaptability of SOGI structures will help to reduce the THDi in the case of variations of the grid frequency, even under highly distorted grid voltage conditions.

A sensorless MPPT algorithm that does not require sensors of the PV panel electrical variables was developed in this study. It is based on the power balance at the DC-link [11] and the improvement of the PV inverter voltage control loop achieved by the use of SOGIs.

The applied techniques allow both a reduced DC-link and a sensorless MPPT algorithm, keeping the performance similar to that of conventional MPPTs, but at a much lower cost.

\section{Two-Stage Grid-Connected PV Inverter}

The two-stage grid-connected PV inverter shown in Figure 1 has been used for validating the theoretical study. It is formed by a flyback DC-DC and a single phase inverter. The inverter connects a single $230 \mathrm{~W}$ PV panel to the single-phase grid $(230 \mathrm{Vrms}, 50 \mathrm{~Hz})$.

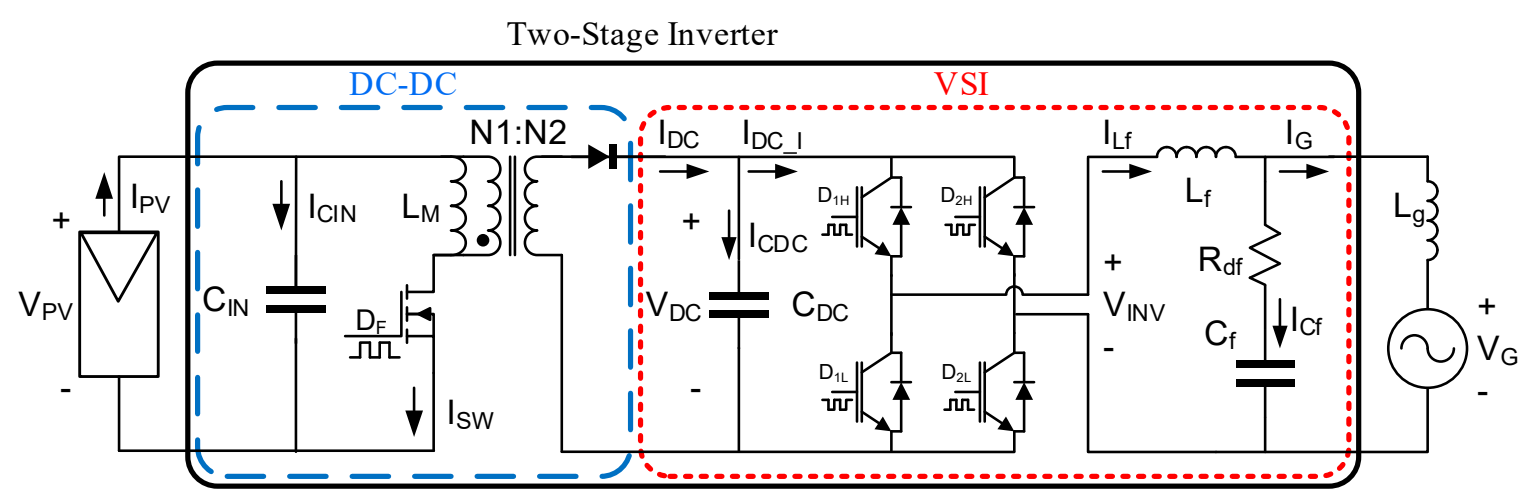

Figure 1. Two-stage grid-connected inverter.

The inverter has a reduced size DC-link. Voltage and current sensors for the measurement of the PV panel voltage, $\mathrm{V}_{\mathrm{PV}}$, and current, $\mathrm{I}_{\mathrm{PV}}$, are available, in order to compare conventional MPPT algorithms, which make use of those sensors, with sensorless MPPT algorithms under the same conditions.

Costs saving associated with a smaller bulk capacitor and to the absence of MPPT sensors depends on several characteristics, but the estimation done for the implemented prototype is detailed in Table A1 of Appendix A.

\subsection{Grid-tied VSI}

The voltage source inverter (VSI) is formed by the DC-link capacitance $\left(\mathrm{C}_{\mathrm{DC}}\right)$, a full bridge of IGBTs and an LCL grid filter. The full-bridge is commutated by means of unipolar sinusoidal pulse width modulation (SPWM). The grid filter was designed following the guidelines of Reference [28]. The values of the inverter are shown in Table 1.

The current $\mathrm{I}_{\mathrm{CDC}}$ has high-frequency current components $\left(\mathrm{I}_{\mathrm{DC}} \mathrm{SW}\right)$ due to the switching of the transistors and a low-frequency current component ( $\left.\mathrm{I}_{\mathrm{DC} \_\mathrm{AC}}\right)$. The frequency of $\mathrm{I}_{\mathrm{DC} \_\mathrm{AC}}$ is twice the grid frequency and causes a voltage ripple at the DC-link $\left(\mathrm{V}_{\mathrm{DC} \_\mathrm{R}}\right)$. In Reference [18] it was shown that the minimum value of $C_{D C}$ is determined by the maximum and minimum permissible voltage at the DC-link caused by $\mathrm{V}_{\mathrm{DC} \_\mathrm{R}}$. However, this criterion does not consider the dynamics of the DC-link [19] and transient voltage variations, that are due to changes in the operation point. The proposed value of the capacitance, $C_{D C}$, to study the effects of a reduced DC-link is designed to limit the peak to peak 
value of $V_{D C \_R}$ to $10 \%$ of $V_{D C}$ at nominal power $\left(P_{G}=230 \mathrm{~W}\right)$, thus the value of the capacitance $C_{D C}$ is calculated following Equation (1).

$$
\mathrm{C}_{\mathrm{DC}} \geq \sqrt{2} \cdot \frac{\mathrm{V}_{\mathrm{G}_{\mathrm{RMS}}} \cdot \mathrm{I}_{\mathrm{G}_{\mathrm{RMS}}}}{\mathrm{V}_{\mathrm{DC} \mathrm{AV}} \cdot \pi \cdot \mathrm{F}_{\mathrm{RDC}} \cdot \mathrm{V}_{\mathrm{DC}} \mathrm{PP}}=\frac{230 \mathrm{~V} \cdot 1 \mathrm{~A}}{380 \mathrm{~V} \cdot \pi \cdot 100 \mathrm{~Hz} \cdot 38 \mathrm{~V}}=50.7 \mu \mathrm{F} \approx 50 \mu \mathrm{F}
$$

Table 1. Values of the Voltage Source Inverter (VSI) stage.

\begin{tabular}{cc}
\hline Item & Value \\
\hline Topology & Single phase, full-bridge \\
RMS Grid Voltage: $\mathrm{V}_{\mathrm{G}}$ & $230 \mathrm{~V}_{\mathrm{AC}}$ \\
Grid frequency: $\mathrm{F}_{\mathrm{G}}$ & $50 \mathrm{~Hz}$ \\
Rated Output Power: $\mathrm{P}_{\mathrm{G}}$ & $230 \mathrm{~W}$ \\
Max Current: $\mathrm{I}_{\mathrm{G}}$ & $1 \mathrm{~A}$ \\
Modulation & Unipolar SPWM \\
Inverter switching Frequency: $\mathrm{F}_{\mathrm{SW}} \mathrm{I}$ & $20 \mathrm{kHz}$ \\
Sampling Frequency: $\mathrm{F}_{\mathrm{S}}$ & $40 \mathrm{kHz}$ \\
Filter Inductance: $\mathrm{L}_{\mathrm{f}}$ & $38 \mathrm{mH}$ \\
Filter Capacitance: $\mathrm{Cf}$ & $330 \mathrm{nF}$ \\
Damping Resistor: $\mathrm{Rf}$ & $50 \Omega$ \\
& $1.5 \mathrm{mH}($ strong grid) \\
Grid Inductance estimation: $\mathrm{L}_{\mathrm{g}}$ & $3 \mathrm{mH}($ standard grid) \\
DC-link Voltage: $\mathrm{V}_{\mathrm{DC}}$ & $6 \mathrm{mH}($ weak grid) \\
DC-link Voltage Ripple: $\mathrm{V}_{\mathrm{DC} \_\mathrm{R}}$ & $380 \mathrm{~V}$ \\
DC-link Capacitance: $\mathrm{C}_{\mathrm{DC}}$ & $10 \%$ of $\mathrm{V}_{\mathrm{DC}}\left(38 \mathrm{~V} \mathrm{~V}_{\mathrm{pk}-\mathrm{pk}}\right)$ \\
\hline
\end{tabular}

\subsection{Step Up DC-DC Converter}

The DC-DC stage, shown in Figure 1, is a Flyback converter designed for boosting the voltage from the $\mathrm{PV}$ panel $\left(\mathrm{V}_{\mathrm{PV}}\right)$ up to the voltage of the $\mathrm{DC}$-link $\left(\mathrm{V}_{\mathrm{DC}}\right)$ and providing high-frequency galvanic isolation between the PV panel and the grid. The converter is designed to work in discontinuous conduction mode $(\mathrm{DCM})$ because the value of the transformer magnetizing inductance $\left(\mathrm{L}_{\mathrm{M}}\right)$ and the physical size of the transformer become smaller [15]. The MPPT algorithm establishes the operation point of this stage since the PV panel voltage is at the input of the DC-DC converter. It is worth pointing out that in the two-stage PV inverter structure the output voltage of the DC-DC converter is regulated by the inverter stage, whereas the panel voltage is controlled by the DC-DC converter following the reference value provided by the MPPT algorithm.

The current $\mathrm{I}_{\mathrm{SW}}$, through the switch of the DC-DC converter, is composed by Equation (2) an average value equal to the PV panel current, $\mathrm{I}_{\mathrm{PV}}$, and a high-frequency component, $\mathrm{I}_{\mathrm{CIN}}$, provided by a low voltage input capacitance, $\mathrm{C}_{\mathrm{IN}}$, following Equation (2).

$$
\mathrm{I}_{\mathrm{SW}}=\mathrm{I}_{\mathrm{PV}}-\mathrm{I}_{\mathrm{CIN}} .
$$

The size of $\mathrm{C}_{\mathrm{IN}}$ depends on the high-frequency current components at the input of the DC-DC converter. Besides, the value of the output capacitance, $C_{D C}$, has an influence on the MPPT performance, since $\mathrm{V}_{\mathrm{PV}}$ is susceptible to the low-frequency voltage ripple at the DC-link voltage, $\mathrm{V}_{\mathrm{DC} \_\mathrm{R}}$. It is worth pointing out that the implementation of a peak current control (PCC) is highly desirable for protecting the power switches from transient overcurrents. The values of the DC-DC converter are detailed in Table 2. 
Table 2. Values of the DC-DC stage.

\begin{tabular}{cc}
\hline Item & Value \\
\hline Topology & Flyback \\
DC Input Voltage: $\mathrm{V}_{\mathrm{PV}}$ & $24 \mathrm{~V}$ to $35 \mathrm{~V}$ at the MPPT \\
DC Output Voltage: $\mathrm{V}_{\mathrm{DC}}$ & $380 \mathrm{~V}$ \\
Rated Input Power: $\mathrm{P}_{\mathrm{PV}}$ & $230 \mathrm{~W}$ \\
Max Input Current: $\mathrm{I}_{\mathrm{PV}}$ & $8 \mathrm{~A}$ \\
Flyback converter switching Frequency: $\mathrm{F}_{\mathrm{SW}} \mathrm{F}$ & $24 \mathrm{kHz}$ \\
Input Capacitance: $\mathrm{C}_{\mathrm{IN}}$ & $4 \mathrm{mF}$ \\
Transformer Turns Ratio: $\mathrm{N}_{\mathbf{N}}$ N1/N2 & $1 / 16$ \\
Transformer Magnetizing Inductance: $\mathrm{L}_{\mathrm{M}}$ & $10 \mu \mathrm{H}$ \\
Conduction Mode & Discontinuous (DCM)
\end{tabular}

\section{Control}

The control of the two-stage inverter has been implemented digitally in a Texas Instruments TMS320F28335 [29] microcontroller with digital signal processor (DSP) extensions at a sampling frequency $\left(\mathrm{F}_{\mathrm{S}}\right)$ of $40 \mathrm{kHz}$. The controllers have been calculated in the continuous domain, having taken into account the digital delays, and then discretized using the bilinear "Tustin" transform. The delay between the sampling and the update of the reference inside the DSP has been done by using a second-order Padé approximation.

It is worth pointing out that the dynamic models used in this control study result from perturbing the averaged variables of the DC-DC converter or of the inverter stage around an operation point, as expressed by Equation (3). In Equation (3), $X$ and $\hat{x}$ denote the operation point value and the small-signal term of the averaged variable, $x$, respectively. The averaging is done in every cycle of the switching frequency.

$$
\mathrm{x}=\mathrm{X}+\hat{\mathrm{x}}
$$

\subsection{Control Scheme of the VSI Stage}

The complete control structure of the VSI is shown in Figure 2.

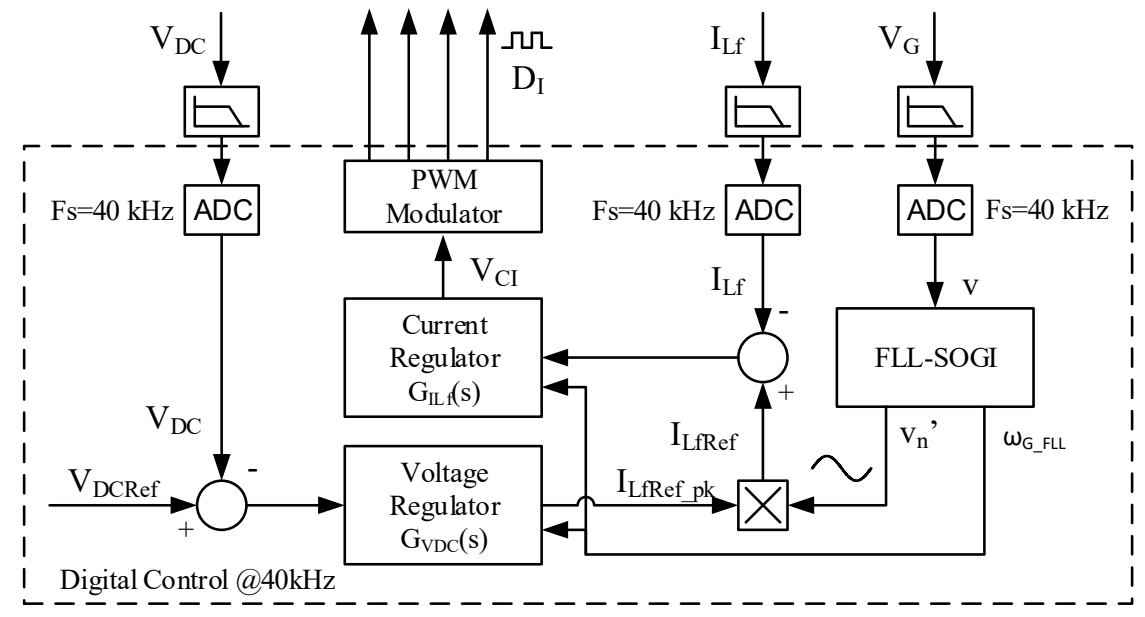

Figure 2. VSI control scheme.

\subsubsection{Synchronization with the Grid}

The synchronization with the grid voltage $\left(\mathrm{V}_{\mathrm{G}}\right)$ has been implemented by means of an SOGI based Frequency Locked Loop (FLL-SOGI) [27], which provides the calculation of the grid frequency in $\mathrm{rad} / \mathrm{s}, \omega_{\mathrm{G}_{-} \mathrm{FLL}}$, a sinusoidal signal in phase with the grid, $\mathrm{v}^{\prime}$, and a sinusoidal signal in quadrature, 
$\mathrm{qv}^{\prime}$. The amplitude of the fundamental harmonic of $\mathrm{V}_{\mathrm{G}}, \mathrm{v}_{\mathrm{pk}}^{\prime}$, is calculated following Equation (4), and a normalized sinusoidal signal in phase with the grid, $\mathrm{v}^{\prime}{ }_{n}$, is obtained in Equation (5).

$$
\begin{gathered}
\mathrm{v}_{\mathrm{pk}}^{\prime}=\sqrt{\mathrm{v}^{\prime 2}+\mathrm{qv}^{\prime 2}} \\
\mathrm{v}_{\mathrm{n}}^{\prime}=\frac{\mathrm{v}^{\prime}}{\mathrm{v}_{\mathrm{pk}}^{\prime}} \rightarrow \mathrm{v}_{\mathrm{n}}^{\prime}(\mathrm{t}) \equiv \cos \left(\omega_{\mathrm{G}_{-} \mathrm{FLL}} \cdot \mathrm{t}\right)
\end{gathered}
$$

\subsubsection{Control of the Current Injected into the Grid}

The control of the current injected into the grid, $\mathrm{I}_{\mathrm{G}}$, is indirectly performed by controlling the current through the inductance Lf of the filter, $\mathrm{I}_{\mathrm{Lf}}$, because the control of $\mathrm{I}_{\mathrm{Lf}}$ is less sensitive to grid impedance variations [30].

A proportional + resonant controller + a harmonics compensator $(\mathrm{P}+\mathrm{R}+\mathrm{HC})$ current regulator, $\mathrm{G}_{\mathrm{ILf}}(\mathrm{s})$, expressed by Equation (6), has been designed following Reference [26] and References [31-34] for tracking the sinusoidal reference of $\mathrm{I}_{\mathrm{Lf}}, \mathrm{I}_{\mathrm{Lf} \text { Ref }}$. Both the resonant and the harmonics compensator have been implemented by means of second-order generalized integrators (SOGI).

$$
\mathrm{G}_{\mathrm{ILf}}(\mathrm{s})=\mathrm{P}_{\mathrm{Lf}}+\mathrm{R}_{\mathrm{Lf}}(\mathrm{s})+\mathrm{HC}(\mathrm{s})=\mathrm{K}_{\mathrm{PLf}}+\sum_{\mathrm{i}=1,3,5,7} \mathrm{~K}_{\mathrm{RLf}[\mathrm{i}]} \frac{\mathrm{K}_{\mathrm{BWRLf}[\mathrm{i}]} \cdot\left(\omega_{\mathrm{G} \_\mathrm{FLL}} \cdot \mathrm{i}\right) \cdot \mathrm{s}}{\mathrm{s}^{2}+\mathrm{K}_{\mathrm{BWRLf}[\mathrm{i}]} \cdot\left(\omega_{\mathrm{G} \_\mathrm{FLL}} \cdot \mathrm{i}\right) \cdot \mathrm{s}+\left(\omega_{\mathrm{G}_{-} \mathrm{FLL}} \cdot \mathrm{i}\right)^{2}}
$$

Taking into account that the value of $\omega_{\mathrm{G}_{\mathrm{F}} \mathrm{FLL}}$ used in Equation (6), provided by the FLL-SOGI, it can be concluded that $\mathrm{G}_{\mathrm{ILf}}$ is adaptive in frequency, allowing high performance even under large variations of the grid frequency. The index ' $i$ ' in Equation (6) represents the corresponding harmonic. The gains of $\mathrm{G}_{\text {ILf }}$ are shown in Table 3.

Table 3. Constants of the regulator $P+R+H C$.

\begin{tabular}{cc}
\hline Constant & Value \\
\hline $\mathrm{K}_{\text {PLf }}$ & 0.65 \\
$\mathrm{~K}_{\text {RLf1 }}$ & 100 \\
$\mathrm{~K}_{\text {BWRLf }}$ & 0.02 \\
$\mathrm{~K}_{\text {RLf3 }}$ & 100 \\
$\mathrm{~K}_{\text {BWRLf3 }}$ & $0.02 / 3$ \\
$\mathrm{~K}_{\text {RLf5 }}$ & 100 \\
$\mathrm{~K}_{\text {BWRL5 }}$ & $0.02 / 5$ \\
$\mathrm{~K}_{\text {RLf7 }}$ & 25 \\
K $_{\text {BWRL7 }}$ & $0.02 / 7$ \\
\hline
\end{tabular}

\subsubsection{Control of the DC-link Voltage $\left(\mathrm{V}_{\mathrm{DC}}\right)$}

A reduced DC-link capacitance leads to the fast dynamics of the $V_{D C}$ control loop at the expense of an increase of the THDi of $\mathrm{I}_{\mathrm{G}}[16,17]$. In Reference [16] a notch filter in the DC-link voltage control loop was implemented to reduce the low-frequency harmonics of $\mathrm{I}_{\mathrm{G}}$. In the current study, the notch filter is implemented by means of SOGIs, achieving adaptation to grid frequency variations. This implementation allows an increase of the crossover frequency of the $V_{D C}$ control loop without increasing the distortion of $\mathrm{I}_{\mathrm{G}}$, even with a high low voltage ripple at the $\mathrm{DC}$-link and under large grid frequency variations. The control scheme of $\mathrm{V}_{\mathrm{DC}}$ is shown in Figure 3. 


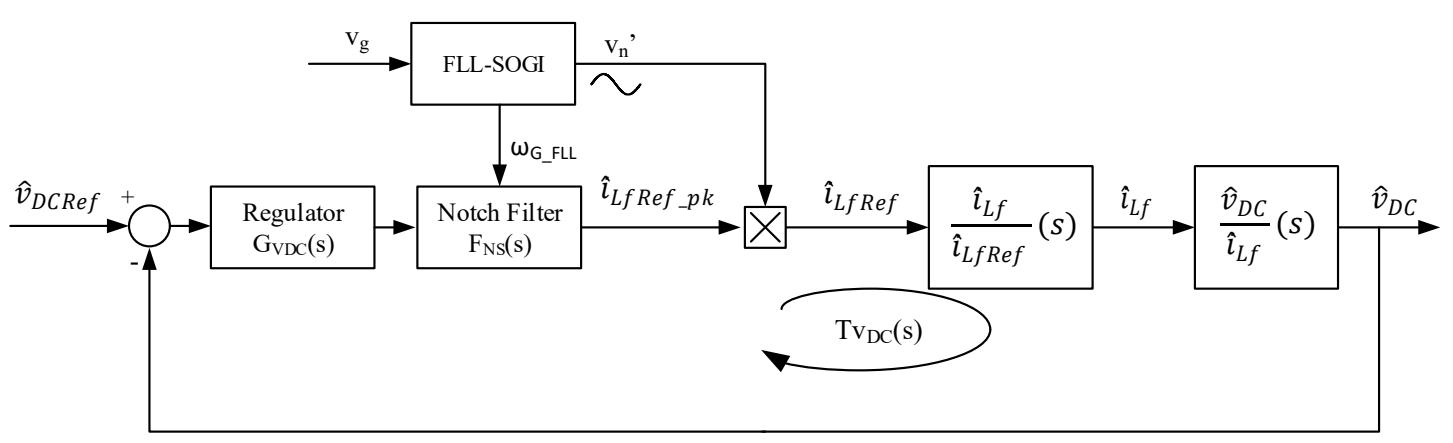

(a)

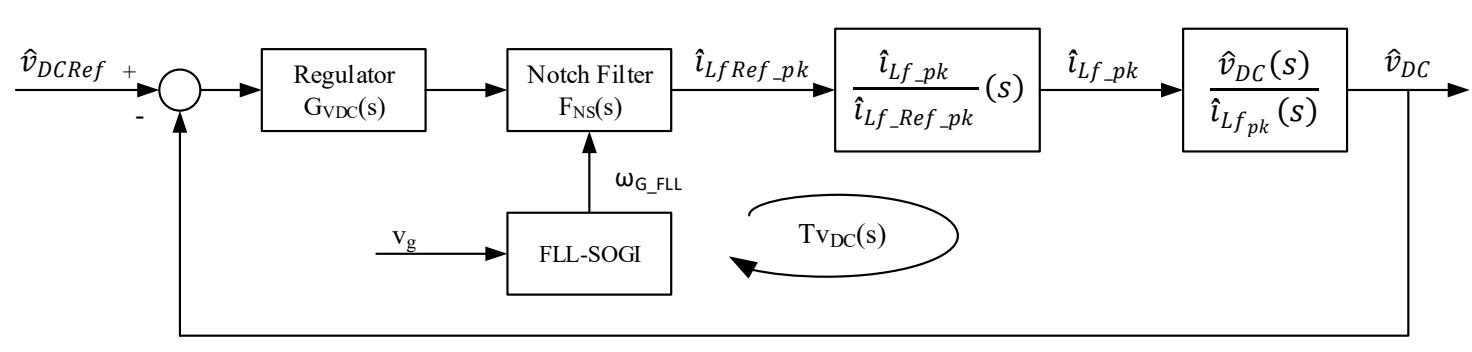

(b)

Figure 3. Control loop of the DC-link voltage $\left(\mathrm{V}_{\mathrm{DC}}\right)$ with second order generalized integrator (SOGI) notch filter: (a) detailed model, (b) equivalent model.

In Figure 3, two small-signal transfer functions play an important role. The first one is the transfer function $\hat{\hat{i}}_{\text {Lf }} / \hat{\mathrm{i}}_{\text {LfRef }}(\mathrm{s})$ in Figure $3 \mathrm{a}$, which is obtained by closing the control loop of $\mathrm{I}_{\mathrm{Lf}}$. This transfer function can be approximated by $(7)$ in Figure $3 b$, where $\omega_{\mathrm{Ci}}$ is the crossover frequency of the VSI current loop.

$$
\frac{\hat{\mathrm{i}}_{\text {Lf_pk }}}{\hat{\mathrm{i}}_{\text {Lf_Ref_pk }}}(\mathrm{s}) \approx \frac{1}{1+\frac{\mathrm{s}}{\omega_{\mathrm{Ci}}}}
$$

In the case of a three-phase grid connected inverter, the derivation of the transfer function from the AC side active current to the DC-link voltage and the adjustment of the voltage loop PI regulator can be found in Reference [35], pages 210-219. In the case of the single-phase inverter under study, an analogous Equation (8) can be derived, based on the power balance and the power perturbation at the DC and AC sides. The transfer function from the peak value of the inverter output current at the AC side to the DC-link voltage can be expressed by Equation (8) after some derivation. Note that Equation (8) consists of a first-order transfer function with an (unstable) right half plane (RHP) pole, $\omega_{P} \_$RHP, whose value depends on the operation point values $\mathrm{V}_{\mathrm{DC}}$ and $\mathrm{I}_{\mathrm{DC}}$.

$$
\frac{\hat{\mathrm{v}}_{\mathrm{DC}}(\mathrm{s})}{\hat{\mathrm{i}}_{\mathrm{Lf} \_\mathrm{pk}}(\mathrm{s})}=\frac{\frac{\mathrm{V}_{\mathrm{G}}}{\sqrt{2} \cdot \mathrm{I}_{\mathrm{DC}}}}{1-\frac{\mathrm{s}}{\left(\frac{\mathrm{I}_{\mathrm{DC}}}{\mathrm{C}_{\mathrm{DC}} \cdot \mathrm{V}_{\mathrm{DC}}}\right)}}=\frac{\frac{\mathrm{V}_{\mathrm{G}}}{\sqrt{2} \cdot \mathrm{I}_{\mathrm{DC}}}}{1-\frac{\mathrm{s}}{\omega_{\mathrm{P} \_\mathrm{RHP}}}} ; \omega_{\mathrm{P}_{-} \mathrm{RHP}}=\frac{\mathrm{I}_{\mathrm{DC}}}{\mathrm{C}_{\mathrm{DC}} \cdot \mathrm{V}_{\mathrm{DC}}}
$$

The loop gain $\mathrm{T}_{\mathrm{VDC}}(\mathrm{s})$ of Figure 3 is tuned by means of the PI regulator $\mathrm{G}_{\mathrm{VDC}}(\mathrm{s})$. Equation (9) provides the crossover frequency, $F_{C} \_V D C$, one decade higher than $\omega_{P_{-}} R_{H P} /(2 \pi)$. Note that an open loop unstable system can be stabilized by feedback only if the loop gain has a gain crossover frequency much higher than the maximum possible value of the unstable open loop pole, FC_VDC $>>\omega_{P_{-} R H P} /(2 \pi)$ in this case. Besides, the value of $F_{C_{-}}$VDC must be much lower than twice the grid frequency $\left(\mathrm{F}_{\mathrm{G}}\right)$, to 
reduce the effect of the low-frequency voltage ripple at the DC-link $\left(f_{\text {ripple }}=2\right.$ Fc_VDC $)$ in the current reference signal $i_{\text {Lf_ref }}$, which could produce an unacceptable distortion of the grid injected current.

$$
\operatorname{Gv}_{\mathrm{DC}}(\mathrm{s})=-0.03902 \cdot\left(\frac{\mathrm{s}+0.6283}{\mathrm{~s}}\right)
$$

It can be observed from Figure 3 that a notch filter, $\mathrm{F}_{\mathrm{NS}}(\mathrm{s})$, is placed in series with the PI controller $\operatorname{Gv}_{D C}(\mathrm{~s})$. The expression of the notch filter transfer function is given by Equation (10). The center frequency of $F_{N S}(s)$ is twice the grid frequency $\left(\omega_{N S}=2 \omega_{G_{-} F L L}\right)$ in order to filter the ripple at $f_{\text {ripple }}$ coming from the sensed DC-link voltage. The tuning of the notch filter is provided by the FLL-SOGI previously described. The constant $\mathrm{K}_{\mathrm{NS}}$ is used to adjust the bandwidth of the filter, $\mathrm{BW}_{\mathrm{NS}}$, as shown in Equation (11). The notch filter allows getting a high enough crossover frequency of the voltage loop with no distortion of the grid injected current. Note that a fast enough DC-link voltage loop is crucial to keep the DC-link voltage within safe values in reduced size DC-links with low capacitance.

$$
\begin{gathered}
\mathrm{F}_{\mathrm{NS}}(\mathrm{s})=\frac{\mathrm{s}^{2}+\omega_{\mathrm{NS}}{ }^{2}}{\mathrm{~s}^{2}+\mathrm{K}_{\mathrm{NS}} \cdot \omega_{\mathrm{NS}} \cdot \mathrm{s}+\omega_{\mathrm{NS}}{ }^{2}} \\
\mathrm{BW}_{\mathrm{NS}} \cdot 2 \pi=\mathrm{K}_{\mathrm{NS}} \cdot \omega_{\mathrm{NS}} \rightarrow \mathrm{K}_{\mathrm{NS}}=\frac{2 \pi \cdot \mathrm{BW}}{\omega_{\mathrm{NS}}}=\frac{100 \cdot 2 \pi}{2 \cdot \mathrm{F}_{\mathrm{G}} \cdot 2 \pi}=1
\end{gathered}
$$

The Bode plots of $\mathrm{T}_{\mathrm{VDC}}(\mathrm{s})$ depicted in Figure $4 \mathrm{a}$ are those obtained when the notch filter, $\mathrm{F}_{\mathrm{NS}}(\mathrm{s})$, placed in series with $\mathrm{Gv}_{\mathrm{DC}}(\mathrm{s})$ isn't used. The PI regulator $\mathrm{G}_{\mathrm{VDC}}(\mathrm{s})(9)$ has been tuned in order to achieve a crossover frequency $\mathrm{F}_{\mathrm{C}_{-} \mathrm{VDC}}=53 \mathrm{~Hz}$, with a phase margin higher than $82^{\circ}\left(\mathrm{PM}>82^{\circ}\right)$ and a gain margin higher than $70 \mathrm{~dB}(\mathrm{GM}>70 \mathrm{~dB})$. The system is stable but the attenuation at $100 \mathrm{~Hz}$ is just $5.5 \mathrm{~dB}$. Therefore, the output of the voltage regulator has a remarkable low-frequency voltage ripple due to $V_{D C \_}$, thus producing a high distortion of the grid current.

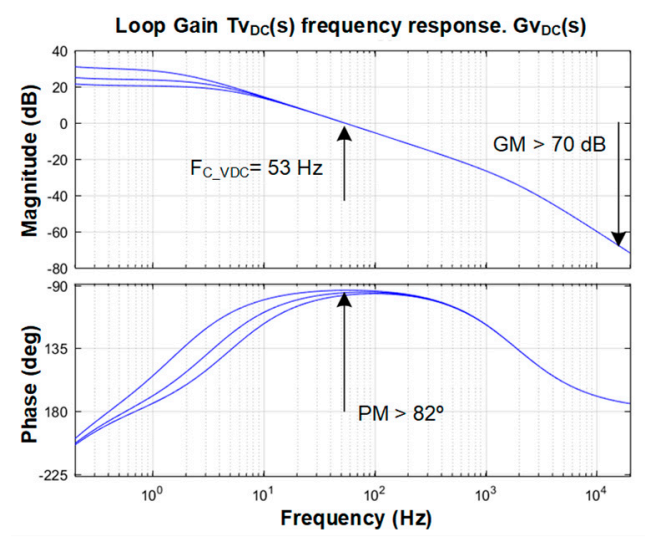

(a)

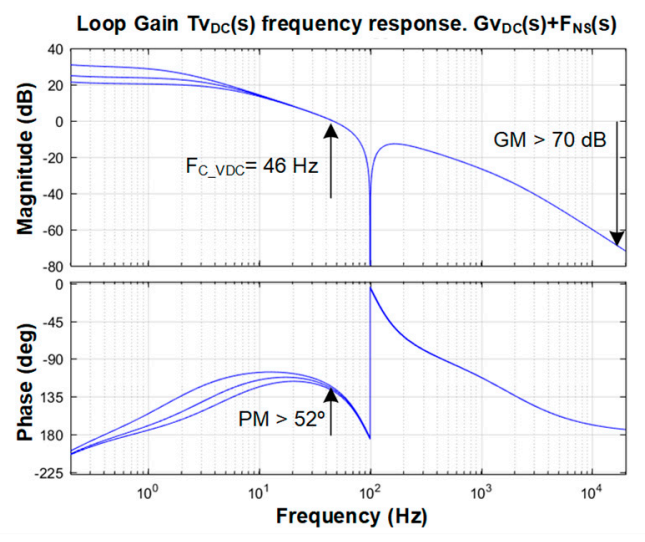

(b)

Figure 4. Loop gain frequency response of $\mathrm{T}_{\mathrm{vDC}}(\mathrm{s}) @ \mathrm{I}_{\mathrm{DC}}=[0.2,0.4,0.6] \mathrm{A} \cdot \mathrm{C}_{\mathrm{DC}}=50 \mu \mathrm{F}$ : (a) without notch SOGI filter, $(\mathbf{b})$ with notch SOGI filter.

Figure $4 \mathrm{~b}$ shows the Bode plots of $\mathrm{T}_{\mathrm{VDC}}(\mathrm{s})$ when the notch filter is used in series with $\mathrm{G}_{\mathrm{VDC}}(\mathrm{s})$. In that case the value of $\mathrm{F}_{\mathrm{C}_{-} \mathrm{VDC}}$ has slightly decreased $\left(\mathrm{F}_{\mathrm{C}_{-} \mathrm{VDC}}=46 \mathrm{~Hz}\right)$, getting high stability margins: $\mathrm{PM}>52^{\circ}$ and $\mathrm{GM}>70 \mathrm{~dB}$. The system is also stable, but the attenuation at $100 \mathrm{~Hz}$ is higher than $100 \mathrm{~dB}$.

\subsection{Control Scheme of the DC-DC Stage}

The control structure of the DC-DC stage is depicted in Figure 5. It is composed by an outer digital voltage loop, regulating $\mathrm{V}_{\mathrm{PV}}$, in cascade with an analog peak current control (PCC) circuit, which sets the peak value of the current, $\mathrm{I}_{\mathrm{SW}}$, through the Flyback converter power transistor. 


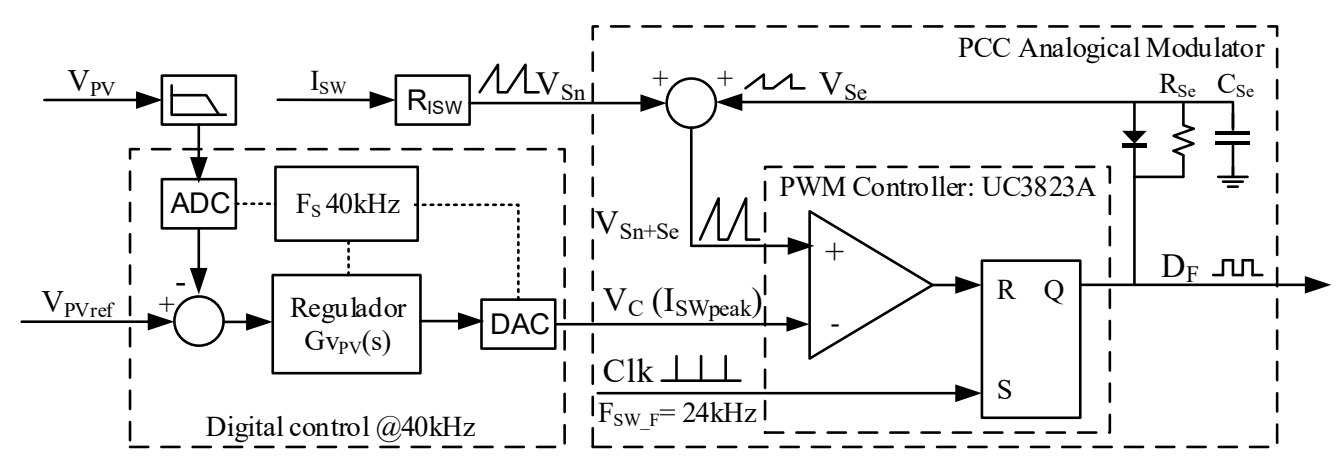

Figure 5. Flyback DC-DC PCC control scheme.

\subsubsection{Peak Current Control of DC-DC Stage}

The PCC control scheme shown in Figure 5 and has been designed following Reference [15]. This control structure is based on the cycle-by-cycle measurement of the current through the transistor, $\mathrm{I}_{\mathrm{SW}}$, of the DC-DC converter. The peak value of $\mathrm{I}_{\mathrm{SW}}$ is limited by the control signal $\mathrm{V}_{\mathrm{C}}$. An external stabilization ramp signal, $\mathrm{V}_{\mathrm{Se}}$, is added to the sensed current signal, $\mathrm{V}_{\mathrm{Sn}}$. This method also provides protection for both the HF transformer and the power transistors against an eventual overcurrent.

The modulation index of the PCC, $\mathrm{mc}=1+\mathrm{Se} / \mathrm{Sn}$ (Equation (13)), is tuned by means of the slope $\mathrm{Se}$ of the external ramp $\mathrm{V}_{\mathrm{Se}}$. The value $\mathrm{Se}=110 \mathrm{~V} / \mathrm{ms}$ accomplishes a dynamic behaviour of $\hat{\mathrm{v}}_{\mathrm{V}_{\mathrm{PV}}} / \hat{\mathrm{v}}_{\mathrm{C}}(\mathrm{s})$ close to that of a first-order system, as it can be observed from Figure 6a. The high $\mathrm{V}_{\mathrm{DC} \_\mathrm{R}}$ ripple value produced by the low size of $C_{D C}$ can change the operation point along the I-V curve of the PV source, degrading the MPPT performance. Therefore, a low susceptibility of $V_{P V}$ to the ripple $V_{D C \_R}$ is required. The open loop susceptibility of $V_{P V}$ to variations of $V_{D C}$ (Equation (14)) at $100 \mathrm{~Hz}$ is lower than $-41.5 \mathrm{~dB}$ as shown in Figure $6 \mathrm{~b}$, therefore $V_{\mathrm{DC} \_}$, that is $10 \%$ of $\mathrm{V}_{\mathrm{DC}}(40 \mathrm{Vpp})$, causes a $\mathrm{V}_{\mathrm{PV}}$ voltage ripple of $340 \mathrm{mVpp}$. It can be concluded that the $100 \mathrm{~Hz}$ ripple at $V_{D C}$ has a low influence on the $\mathrm{PV}$ voltage. Therefore, the sensing of $\mathrm{V}_{\mathrm{PV}}$ could be avoided and still a good MPPT would be obtained.

$$
\begin{gathered}
S_{N}=R_{i} \frac{V_{P V}}{L_{m}} \\
F_{M}=\frac{1}{\left(S_{n}+S_{e}\right) \cdot T_{S_{-} \_F}}=\frac{1}{m_{C} \cdot S_{n} \cdot T_{S_{W_{-}} F}} \\
A(s)=\left.\frac{\hat{v}_{V_{P V}}(s)}{\hat{v}_{D C}(s)}\right|_{\hat{v}_{C}=0}
\end{gathered}
$$

\subsubsection{PV Panel Voltage $\left(\mathrm{V}_{\mathrm{PV}}\right)$ Control Loop in the Conventional MPPT}

The reference of $\mathrm{V}_{\mathrm{PV}}\left(\mathrm{V}_{\mathrm{PVRef}}\right)$ is updated at the sampling frequency of the MPPT, $\mathrm{F}_{\mathrm{MPPT}}$. The PV panel voltage control loop is implemented digitally and its control scheme is depicted in Figure 7. The sampling frequency of the control loop (Fs) is $40 \mathrm{kHz}$. This control loop is adjusted by means the PI regulator $\mathrm{G}_{\mathrm{VPV}}(\mathrm{s})$, whose values are shown by Equation (15). The crossover frequency, $\mathrm{Fc}_{\mathrm{VPV}}$, of the loop gain $\mathrm{T}_{\mathrm{VPV}}(\mathrm{s})$ must be much higher than $\mathrm{F}_{\mathrm{MPPT}}$ so that $\mathrm{V}_{\mathrm{PV}}$ can track $\mathrm{V}_{\mathrm{PV} \text { ref. }}$. The transfer function $\hat{\mathrm{V}}_{\mathrm{VV}} / \hat{\mathrm{v}}_{\mathrm{C}}(\mathrm{s})$ is the closed loop of the PCC and $\hat{\mathrm{v}}_{\mathrm{V}_{\mathrm{PV}}} / \hat{\mathrm{v}}_{\mathrm{C}}(\mathrm{s})$ is the open loop susceptibility of $\mathrm{V}_{\mathrm{PV}}$ to the variations of $\mathrm{V}_{\mathrm{DC}}$.

As it can be observed from the Bode plots of the loop $\mathrm{T}_{\mathrm{VPV}}(\mathrm{s})$ in Figure 8a, the crossover frequency $\mathrm{F}_{\mathrm{VPV}}$ achieved by $\mathrm{G}_{\mathrm{VPV}}(\mathrm{s})$ is higher than $100 \mathrm{~Hz}$. Therefore, an MPPT algorithm running at $\mathrm{F}_{\mathrm{MPPT}}=10 \mathrm{~Hz}$ is suitable Figure $8 \mathrm{~b}$ shows that the presence of this control loop reduces the susceptibility $\hat{\mathrm{V}}_{\mathrm{V}_{\mathrm{PV}}} / \hat{\mathrm{V}}_{\mathrm{DC}}(\mathrm{s})(16)$ at $100 \mathrm{~Hz}$ down to $-55 \mathrm{~dB}$, therefore the voltage ripple in $\mathrm{V}_{\mathrm{PV}}$ caused by $\mathrm{V}_{\mathrm{DC} \_\mathrm{R}}$ is $71 \mathrm{mVpp}$. Note that the use of a control loop of $\mathrm{V}_{\mathrm{PV}}$ reduces the sensitivity of $\mathrm{V}_{\mathrm{PV}}$ to the $100 \mathrm{~Hz}$ ripple 
in $\mathrm{V}_{\mathrm{DC}}$ in a factor of around 5: The ripple in $\mathrm{V}_{\mathrm{PV}}$ is $71 \mathrm{mVpp}$ with voltage loop compared with 340 $\mathrm{mVpp}$ with only PCC loop.

$$
\begin{gathered}
\mathrm{G}_{\mathrm{VPV}}(\mathrm{s})=-1.8345\left(\frac{\mathrm{s}+350}{\mathrm{~s}}\right) \\
\mathrm{A}_{\mathrm{CL}}(\mathrm{s})=\left.\frac{\hat{\mathrm{V}}_{\mathrm{PV}}(\mathrm{s})}{\hat{\mathrm{V}}_{\mathrm{DC}}(\mathrm{s})}\right|_{\hat{\mathrm{v}}_{\text {PVRef }}=0}
\end{gathered}
$$

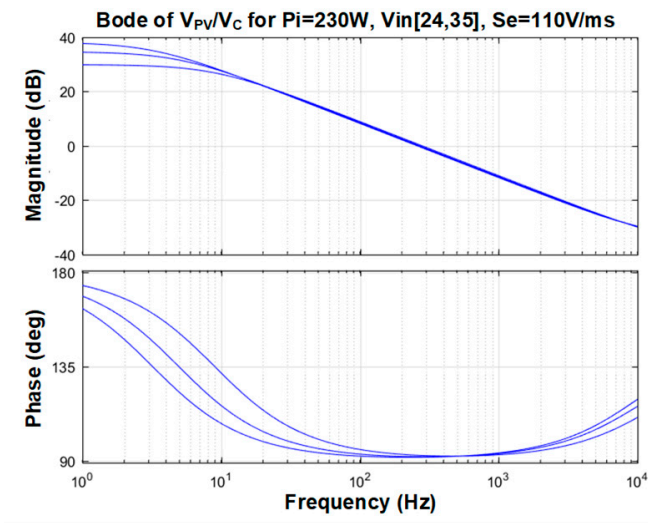

(a)

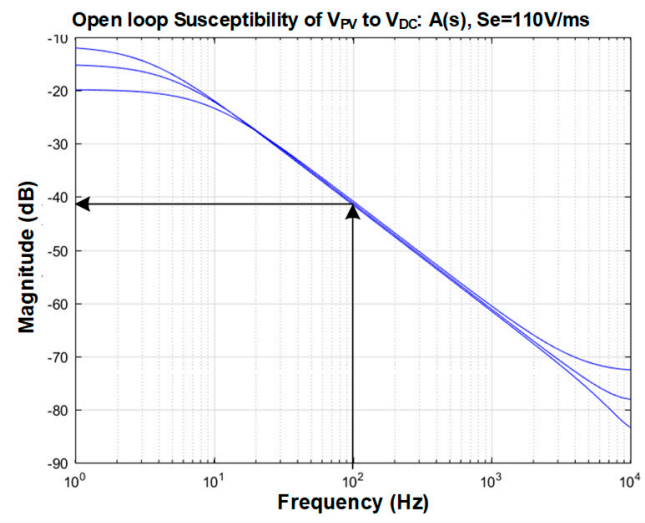

(b)

Figure 6. Frequency response of the PCC: (a) closed loop $\hat{\mathrm{V}}_{\mathrm{V}_{\mathrm{PV}}} / \hat{\mathrm{V}}_{\mathrm{C}}(\mathrm{s})$ response and (b) open loop susceptibility: $\mathrm{A}(\mathrm{s}) . \mathrm{V}_{\mathrm{PV}} \in[24,30,35] \mathrm{V}, \mathrm{P}_{\mathrm{PV}}=230 \mathrm{~W}, \mathrm{Se}=110 \mathrm{~V} / \mathrm{ms}$.

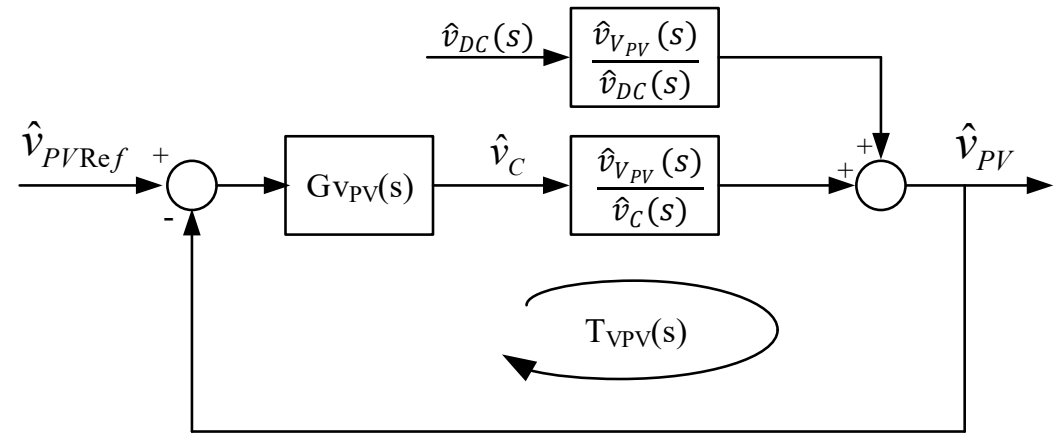

Figure 7. $\mathrm{V}_{\mathrm{PV}}$ control loop.

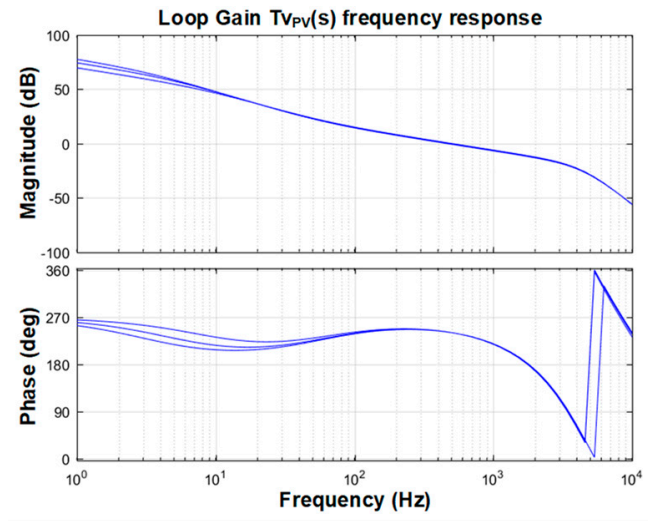

(a)

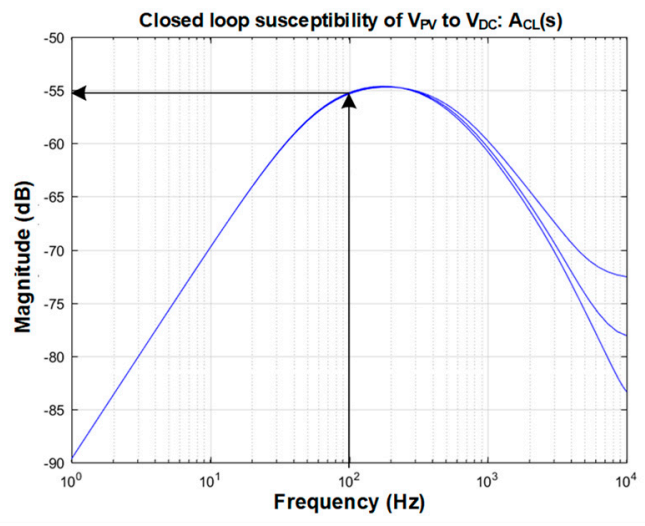

(b)

Figure 8. Frequency response of $\mathrm{V}_{\mathrm{PV}}$ control loop: (a) $\mathrm{T}_{\mathrm{VPV}}(\mathrm{s})$ loop gain of the $\mathrm{V}_{\mathrm{PV}}$ control loop and (b) closed loop susceptibility, $\mathrm{A}_{\mathrm{CL}}(\mathrm{s}) . \mathrm{V}_{\mathrm{PV}}=[24,30,35] \mathrm{V}, \mathrm{P}_{\mathrm{PV}}=230 \mathrm{~W}, \mathrm{Se}=110 \mathrm{~V} / \mathrm{ms}$. 


\section{MPPT Implementation without $\mathrm{V}_{\mathrm{PV}}$ and $\mathrm{I}_{\mathrm{PV}}$ Sensors}

The conventional implementations of MMPT algorithms use current and voltage sensors to measure the voltage $\left(\mathrm{V}_{\mathrm{PV}}\right)$ and the current $\left(\mathrm{I}_{\mathrm{PV}}\right)$ of the PV source as it is shown in Figure 9 . The use of voltage and current sensors increases the cost of the power converter. Sensorless MPPT algorithms have been developed [10-13] in order to reduce the number of sensors, yielding a cost reduction. In [11] a sensorless MPPT implementation based on the power balance at the DC-link was presented, which relies on the fact that the power injected into the grid $\left(\mathrm{P}_{\mathrm{G}}\right)$ can be considered almost equal to the power extracted from the $\mathrm{PV}$ panels, $\mathrm{P}_{\mathrm{G}} \approx \mathrm{P}_{\mathrm{PV}}$. In that implementation, the reference of the current injected into the grid $\left(\mathrm{I}_{\mathrm{G}}\right)$ is used as an estimation of $\mathrm{P}_{\mathrm{G}}$. This reference current depends on the control loop of $\mathrm{V}_{\mathrm{DC}}$ so that the sampling frequency of the MPPT algorithm ( $\left.\mathrm{F}_{\mathrm{MPPT}}\right)$ is limited by the dynamics of that loop. Besides, the reference of $\mathrm{I}_{\mathrm{G}}$ is sensitive to the variations of the grid voltage and has a low-frequency ripple due to $\mathrm{V}_{\mathrm{DC} \_\mathrm{R}}$. Moreover, the method explained in Reference [11] is based on the assumption that the amplitude of the grid voltage is stable.

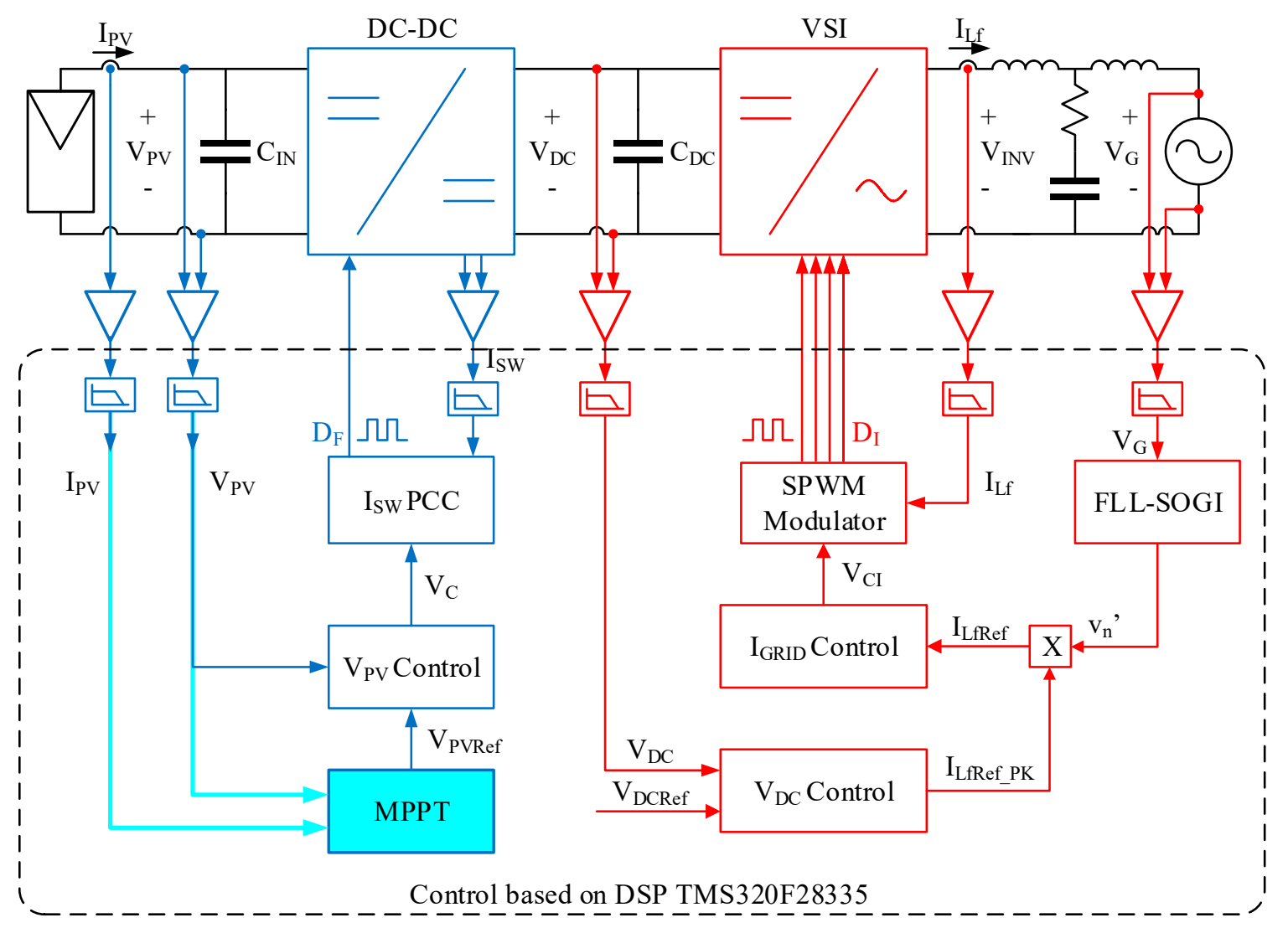

Figure 9. Conventional MPPT implementation.

A sensorless MPPT implementation shown in Figure 10 is proposed in this work. In this implementation, there is neither $\mathrm{V}_{\mathrm{PV}}$ nor $\mathrm{I}_{\mathrm{PV}}$ sensors and it is assumed that the power injected into the grid is almost equal to the power extracted from the PV panels, $\mathrm{P}_{\mathrm{G}} \approx \mathrm{P}_{\mathrm{PV}}$, as in Reference [11]. A novelty of this research is that it takes de advantages of the PCC of the DC-DC stage and some SOGI based enhancements applied to the control of the VSI stage to improve the performance of the MPPT implementation. 


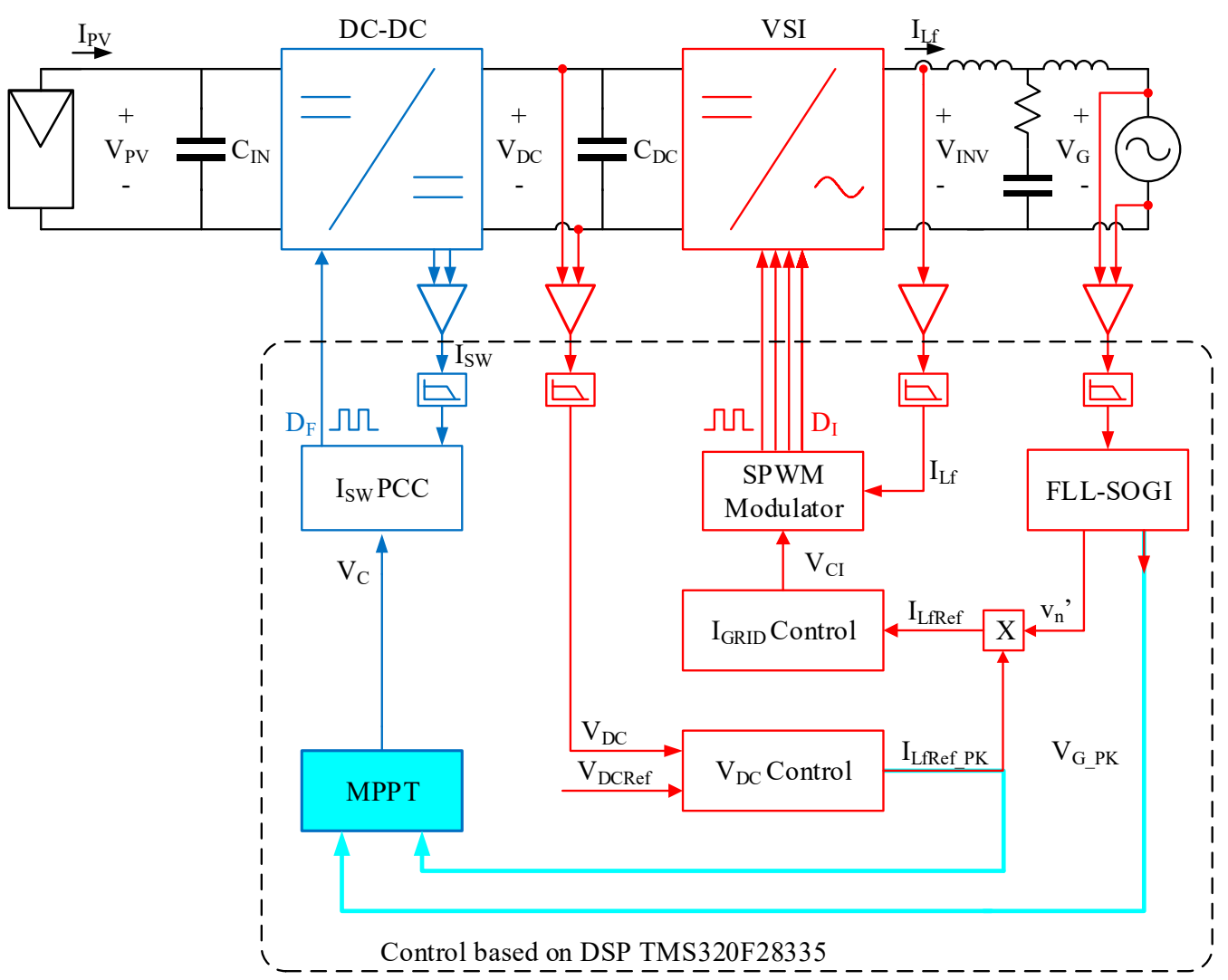

Figure 10. Proposed sensorless MPPT implementation.

A perturb and observe ( $\mathrm{P}$ and $\mathrm{O}$ ) algorithm [36] has been programmed in both the conventional (Figure 10) and the proposed sensorless (Figure 11) MPPT algorithms to compare the performance of both implementations. Both implementations use the grid frequency as a time-base to execute the MPPT algorithm. This technique increases the rejection of the disturbances caused by $\mathrm{V}_{\mathrm{DC} \_\mathrm{R}}$. In previous applications of a similar technique [12], the MPPT algorithm was executed at twice the grid frequency, but that sampling frequency is too fast for the control loops implemented in the proposed sensorless algorithm. In the present study, the MPPT algorithm was executed once every five cycles of the grid, yielding $\mathrm{F}_{\mathrm{MPPT}}=10 \mathrm{~Hz}$.

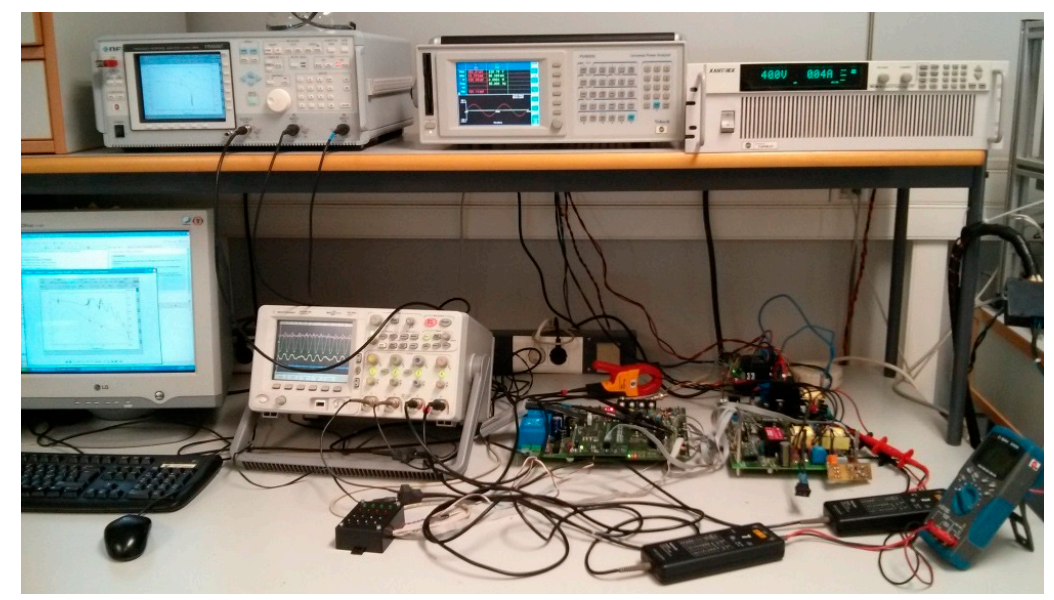

Figure 11. Experimental setup. 
In the conventional implementation, the MPPT algorithm provides the reference of $\mathrm{V}_{\mathrm{PV}}\left(\mathrm{V}_{\mathrm{PV} \_ \text {Ref }}\right)$ to the $\mathrm{V}_{\mathrm{PV}}$ control loop. In the proposed sensorless MPPT, both the $\mathrm{V}_{\mathrm{PV}}$ sensor and the $\mathrm{V}_{\mathrm{PV}}$ control loop have been removed, so that the MPPT provides the reference Vc to the analog PCC.

\subsection{Estimation of the Power Injected into the Grid in the Sensorless MPPT}

The reference $\mathrm{I}_{\text {Lf_Ref_PK }}$ is the peak value of the current injected into the grid, being proportional to $P_{G}$ when the amplitude of the grid voltage is a static value. The signal $I_{L f \_R e f}$ PK may have a remarkable low-frequency voltage ripple due to $\mathrm{V}_{\mathrm{DC} \_}$, thus producing a high distortion of the grid injected current along with a disturbance in the estimation of $P_{G}$. The SOGI based notch filter $F_{N S}(s)$ in series with the regulator $\mathrm{G}_{\mathrm{VDC}}(\mathrm{s})$ shown in Figure 3 is used to filter out that ripple. The use of the notch filter also enables a high crossover frequency of $\mathrm{T}_{\mathrm{VDC}}(\mathrm{s})$ without increasing the ripple in $\mathrm{I}_{\mathrm{Lf} \_ \text {Ref_PK, }}$ which is useful to implement a fast MPPT algorithm. The crossover frequency of $\mathrm{T}_{\mathrm{VDC}}(\mathrm{s})$ is $\mathrm{F}_{\mathrm{C}_{-} \mathrm{VDC}}=45 \mathrm{~Hz}$ so that an MPPT of $\mathrm{F}_{\mathrm{MPPT}}=10 \mathrm{~Hz}$ can be implemented.

The estimation of $\mathrm{P}_{\mathrm{G}}, \mathrm{P}_{\mathrm{G} \text { _est }}$, depends on $\mathrm{I}_{\mathrm{G}}$ and on the grid voltage RMS value $\left(\mathrm{V}_{\mathrm{G}}\right)$ so that variations of $\mathrm{V}_{\mathrm{G}}$ perturb the calculations of $\mathrm{P}_{\mathrm{G}_{-} \text {est. }}$. To overcome this issue, the value of the signal $\mathrm{v}_{\mathrm{pk}}^{\prime}$ is used to calculate the estimation of $\mathrm{P}_{\mathrm{G}}$ as it is shown in Equation (17). The signal $\mathrm{v}_{\mathrm{pk}}^{\prime}$ is the amplitude of the fundamental of $\mathrm{V}_{\mathrm{G}}$ and is provided by the FLL-SOGI, not requiring additional computational resources. The signal $\mathrm{v}_{\mathrm{pk}}$ has very low sensitivity to the distortion of the grid voltage because it is naturally filtered by the FLL-SOGI.

$$
\mathrm{P}_{\mathrm{G}_{-} \text {est }}=\frac{\mathrm{v}_{\mathrm{pk}}^{\prime}}{\sqrt{2}} \cdot \frac{\mathrm{I}_{\text {LfRef_PK }}}{\sqrt{2}}=\frac{\mathrm{v}_{\mathrm{pk}}^{\prime} \cdot \mathrm{I}_{\mathrm{LfRef} \_\mathrm{PK}}}{2} \approx \mathrm{P}_{\mathrm{PV}}
$$

\subsection{Implementation of the Perturb and Observe (PEO) Algorithm}

The conventional MPPT algorithm uses the measurements of $\mathrm{V}_{\mathrm{PV}}$ and $\mathrm{I}_{\mathrm{PV}}$ to set the operation point of the PV source. The algorithm increases or decreases $V_{\text {PV_Ref }}$ in perturbation steps of a value $\Delta \mathrm{V}_{\mathrm{PV} \_}$Ref to move the operation point along the I-V curve. In the sensorless implementation shown in Figure 10, instead of the measurements of $\mathrm{V}_{\mathrm{PV}}$ and $\mathrm{I}_{\mathrm{PV}}$, the value of $\mathrm{P}_{\mathrm{G}_{-} \text {est }}$ expressed by Equation (17) was used. In Reference [11] it was proposed to manage the duty cycle of the switches $\left(D_{F}\right)$ of the DC-DC to move the operation point along the I-V curve. In inverters with a reduced DC-link, the high susceptibility of $\mathrm{V}_{\mathrm{PV}}$ to the ripple $\mathrm{V}_{\mathrm{DC} \_\mathrm{R}}$ disturbs the operation point in the PV panel.

In the proposed sensorless MPPT, the value of $\mathrm{I}_{\mathrm{PV}}$ is indirectly set by means of the reference signal of the PCC loop, Vc. The use of PCC has two functions: reducing the susceptibility of $\mathrm{V}_{\mathrm{PV}}$ to the ripple $\mathrm{V}_{\mathrm{DC} \_\mathrm{R}}$ and protecting the DC-DC converter from overcurrents.

The variable $V_{c}$ is increased or decreased in small steps of a value $\Delta V_{c}$. It is worth pointing out that an increase of $\mathrm{Vc}$ causes an increase of $\mathrm{I}_{\mathrm{PV}}$, moving the PV operation point to the left of the I-V curve, whereas a decrease of $\mathrm{Vc}$ moves the PV operation point to the right of the I-V curve.

\section{Results}

Figure 11 depicts the experimental setup. The laboratory tests have been performed using the two-stage inverter presented in Figure 1. The inverter under test was designed for connecting a single PV panel of $230 \mathrm{~W}$ to the single phase grid $\left(230 \mathrm{~V}_{\mathrm{RMS}} @ 50 \mathrm{~Hz}\right)$ and has a DC-link with the capacitance calculated in (1), $C_{D C}=50 \mu \mathrm{F}$. The challenge of using such a small value of $C_{D C}$ is to keep a low distortion of the grid current and small transient overvoltages at the DC-link. The control of the two-stage inverter has been implemented digitally in a Texas Instruments TMS320F28335 DSP [30] at a sampling frequency $\left(\mathrm{F}_{\mathrm{S}}\right)$ of $40 \mathrm{kHz}$.

The grid was emulated by means of a Cinergia GE\&EL 50 grid emulator and electronic load. The voltage waveform was programmed according to the test waveform described in the international standard IEC-61000-4-7 [37], which has a value: $\mathrm{THD}_{\mathrm{V}}=1.2 \%$. The PV panel has been emulated by means of an AMETEK TerraSAS ETS1000X10D PV simulator. 


\subsection{Control of the VSI}

\subsubsection{Transients of the DC-link Voltage}

Figure 12 shows the transient response of the $\mathrm{DC}$-link voltage $\left(\mathrm{V}_{\mathrm{DC}}\right)$ and the current injected into the grid $\left(\mathrm{I}_{\mathrm{G}}\right)$ when the PV power steps from $150 \mathrm{~W}$ up to $200 \mathrm{~W}$. The results shown in Figure 12a were obtained with a crossover frequency $\mathrm{FC}_{-} \mathrm{VDC}=10 \mathrm{~Hz}$, yielding an overvoltage in $\mathrm{V}_{\mathrm{DC}}$ of $53 \mathrm{~V}$ from its steady-state value. The response in Figure $12 \mathrm{~b}$ is obtained with a crossover frequency F $\mathrm{F}_{-} \mathrm{VDC}=45 \mathrm{~Hz}$. The response in Figure $12 \mathrm{~b}$ was close to five times faster and the overvoltage is only $15 \mathrm{~V}$, which represents a reduction of $72 \%$.

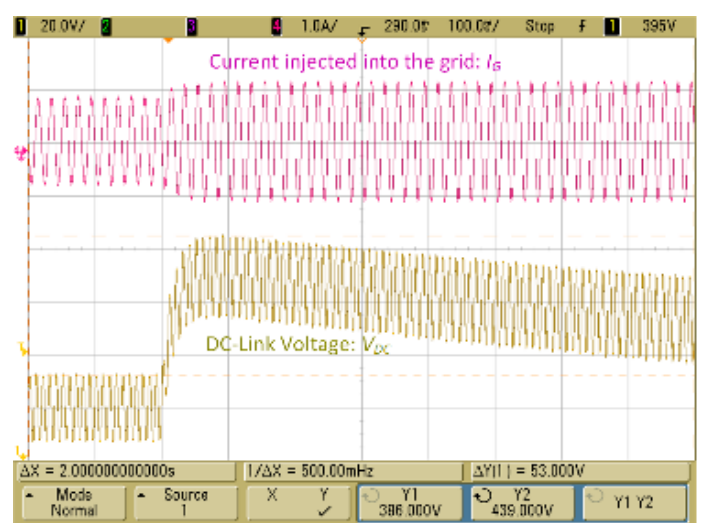

(a)

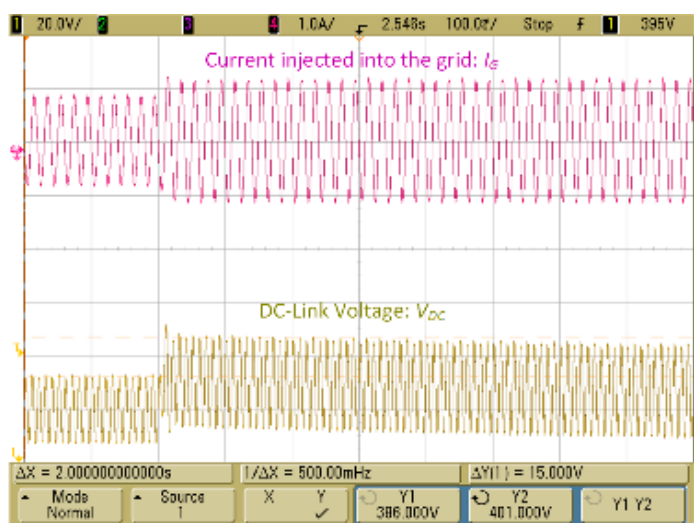

(b)

Figure 12. Power step from $150 \mathrm{~W}$ to $200 \mathrm{~W} . \mathrm{C}_{\mathrm{DC}}: 50 \mu \mathrm{F}$. (a): $\mathrm{FC}_{\mathrm{TVDC}}$ : $10 \mathrm{~Hz}$. (b): $\mathrm{FC}_{\mathrm{TVDC}}: 45 \mathrm{~Hz}$.

\subsubsection{Influence of the SOGI Notch in the Distortion of the Current Injected to the Grid}

The increment of the crossover frequency $F_{C}$ VDC involves a higher susceptibility to $V_{D C \_}$, which increases the harmonic distortion of the current injected into the grid (THDi). Figure 13 depicts the current injected into the grid $\left(\mathrm{I}_{\mathrm{G}}\right)$ using two different regulators for controlling $\mathrm{V}_{\mathrm{DC}}$. In Figure $13 \mathrm{~b}$, the regulator $G_{V D C}(s)$ of the $V_{D C}$ control loop is the PI shown in Equation (9) with a crossover frequency $F_{-} \_V D C=53 \mathrm{~Hz}$. The waveform of $\mathrm{I}_{\mathrm{G}}$ in Figure $13 \mathrm{~b}$ was obtained using the same PI regulator, but in series with the SOGI notch filter $\mathrm{F}_{\mathrm{NS}}(\mathrm{s})$ shown in Equation (10), centered at $100 \mathrm{~Hz}$. The crossover frequency has been slightly reduced, $\mathrm{F}_{-} \mathrm{VDC}=45 \mathrm{~Hz}$, taking into account the addition of $\mathrm{F}_{\mathrm{NS}}(\mathrm{s})$.

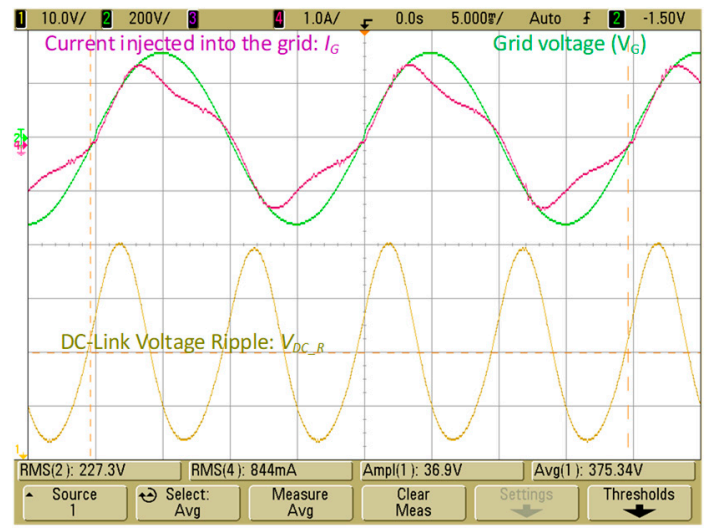

(a)

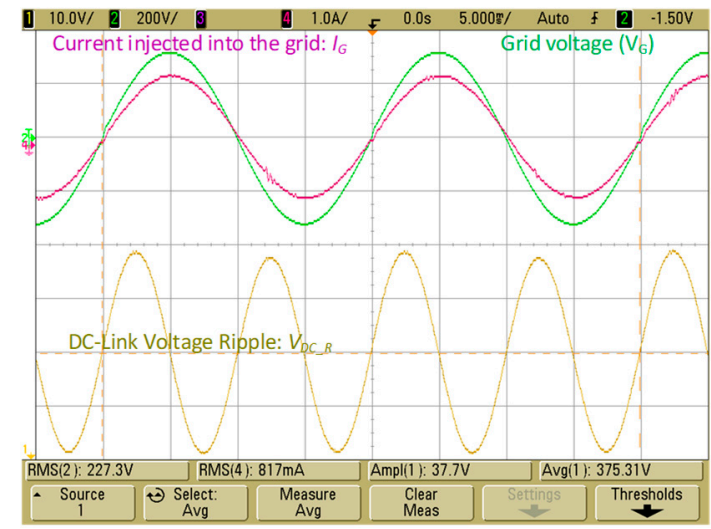

(b)

Figure 13. THDi of the current injected into the grid at $P_{G}=200 \mathrm{~W}$. Grid: EN-61000-4-7 (1.2\% THDv). $F_{C} \_$VDC $=50$ Hz. (a): PI Reg.: $\mathrm{Gv}_{\mathrm{DC}}(\mathrm{s}) .(\mathbf{b}):$ PI Reg. + Notch filter: $\mathrm{Gv}_{\mathrm{DC}}(\mathrm{s})+\mathrm{F}_{\mathrm{NS}}(\mathrm{s})$. 
Both tests have been performed injecting $200 \mathrm{~W}$ to the grid. The controller of the current injected into the grid $\left(\mathrm{I}_{\mathrm{G}}\right)$ is formed by the $\mathrm{P}+\mathrm{R}$ regulator in series with the HC expressed by Equation (6). The resulting values of the THDi are $21.51 \%$ and $0.96 \%$, respectively. This result indicates the effectiveness of the notch filter for reducing the THDi in spite of the small DC-link.

The following tests of the THDi have been performed for values of $\mathrm{P}_{\mathrm{G}}$ in the range $\mathrm{P}_{\mathrm{G}}=[40,180]$ $\mathrm{W}$. The results are shown in Figure 14. The purple trace represents the values of THDi obtained without the SOGI notch $\mathrm{F}_{\mathrm{NS}}(\mathrm{s})$ and the green trace represents the values obtained with $\mathrm{F}_{\mathrm{NS}}(\mathrm{s})$. The THDi without notch varies from $21.51 \%$ to $22.43 \%$, clearly exceeding the limits of the IEEE519 standard [4] (5\%), shown by the red line. The values of the THDi obtained with $\mathrm{F}_{\mathrm{NS}}(\mathrm{s})$ vary from $0.96 \%$ to $3.14 \%$, widely complying with IEEE519 in the whole range of $\mathrm{P}_{\mathrm{G}}$ values. In all the measurements the distortion of the grid voltage is $\mathrm{THDv}=1.2 \%$.

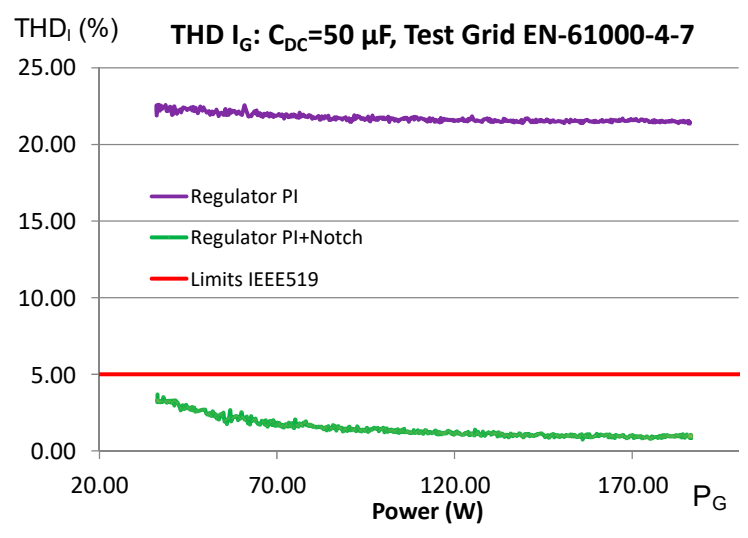

Figure 14. THD of $\mathrm{I}_{\mathrm{G}}$. Grid: EN-61000-4-7 (1.2\% THDv). Linear sweep of power injected into the grid $\left(\mathrm{P}_{\mathrm{G}}\right)$ from $40 \mathrm{~W}$ to $180 \mathrm{~W}$ at grid frequency $\mathrm{F}_{\mathrm{G}}=50 \mathrm{~Hz}$.

\subsubsection{Loop Gain Measurement}

The loop gain $\mathrm{T}_{\mathrm{VDC}}(\mathrm{s})$ has been validated by means of loop gain measurement procedures [38-40]. The setup of the test is shown in Figure 15. An NF FRA5097 frequency response analyzer (FRA) is configured to perform an AC sweep from $2 \mathrm{~Hz}$ to $20 \mathrm{kHz}$. The signal generated by the oscillator of the FRA ( $\mathrm{v}_{\mathrm{OSC}} \mathrm{A}$ ) is acquired by the DSP, which carries out the control of the inverter through an internal 12-bit ADC. The acquired signal ( $\mathrm{v}_{\mathrm{OSC}}$ ) was digitally injected into the control loop as a perturbation. Both, $\mathrm{v}_{\mathrm{DC}}$ and $\mathrm{v}_{\mathrm{DC}}+\mathrm{v}_{\mathrm{OSC}}$ signals were adapted digitally to be loaded into the pulse width modulation (PWM) unit of the DSP. The offset of the signals was removed through digital high pass filters, and then the amplitudes are digitally adjusted to maximize the resolution of the PWM. The PWM signals $\left(v_{D C}\right)_{P W M}$ and $\left(v_{D C}+v_{O S C}\right)_{P W M}$ were measured by the FRA. The PWM signals were filtered by the FRA through its internal tracking filter. The loop gain measurement of $\mathrm{T}_{\mathrm{VDC}}(\mathrm{s})$, shown in Figure 16, was performed at $\mathrm{P}_{\mathrm{G}}=230 \mathrm{~W}$. The results show the similarity between the experimental and theoretical Bode plots of $\mathrm{T}_{\mathrm{VDC}}(\mathrm{s})$.

\section{2. $M P P T$}

The performance of the sensorless "perturb and observe" (P and O) MPPT algorithm presented in this study has been compared to a conventional implementation, which uses sensors to measure $\mathrm{V}_{\mathrm{PV}}$ and $\mathrm{I}_{\mathrm{PV}}$. The experimental tests have carried out to measure the start-up time until the maximum power point (MPP) was reached, and the performance at the MPPT under irradiation transients. All the tests were performed with an MPPT sampling frequency, $\mathrm{F}_{\mathrm{MPPT}}=10 \mathrm{~Hz}$. The perturbation step value programmed in the conventional implementation was $\Delta \mathrm{V}_{\mathrm{PV} \_ \text {Ref }}=300 \mathrm{mV}$. In the sensorless MPPT the perturbation step was $\Delta \mathrm{Vc}_{\mathrm{c}}=12.5 \mathrm{mV}$, which corresponds to a $250 \mathrm{~mA}$ step in $\mathrm{I}_{\mathrm{PV}}$ in the operation region close to the MPP. It is worth pointing out that different values are perturbed in both 
MPPTs (either $\mathrm{V}_{\mathrm{PV} \_ \text {Ref }}$ or $\triangle \mathrm{Vc}$ ) and that the DC-DC converter operates in discontinuous conduction mode. Both facts prevent finding an equivalent value of the perturbation step in both MPPTs.

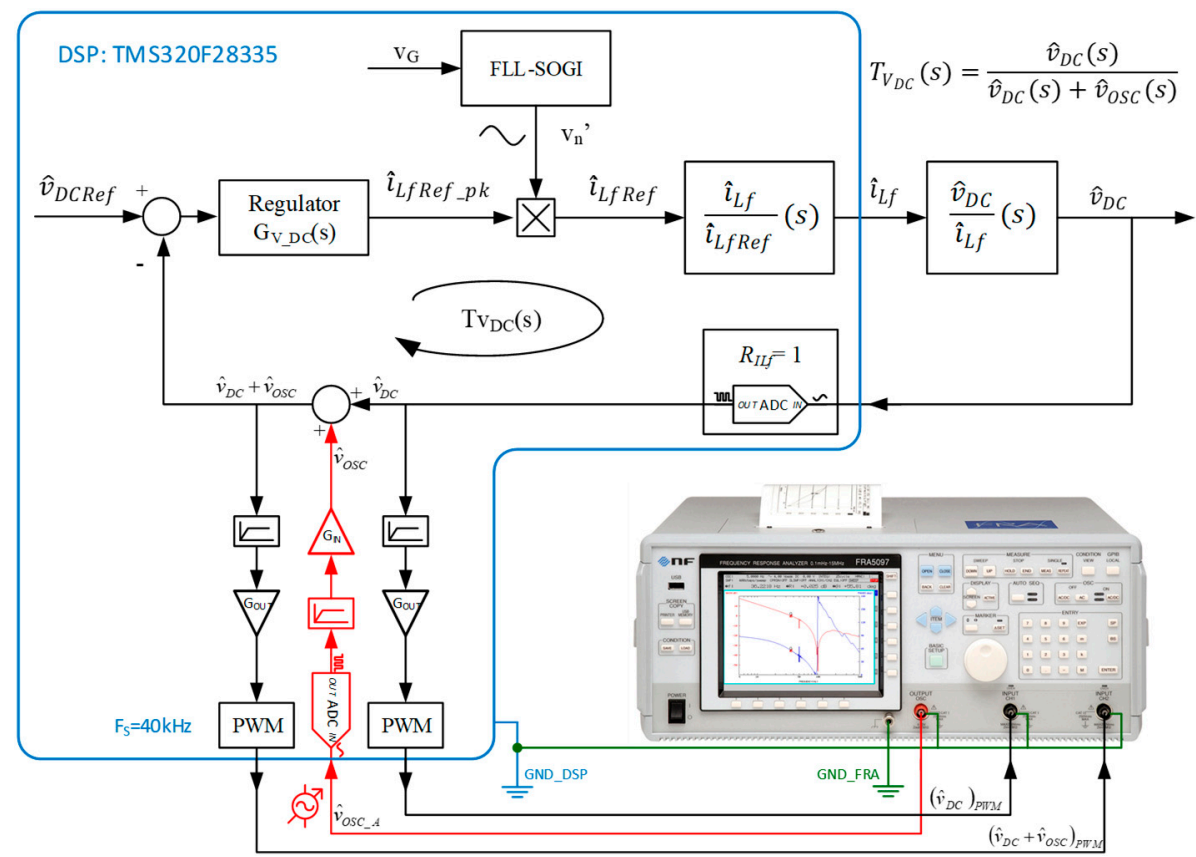

Figure 15. Loop gain measurement setup.

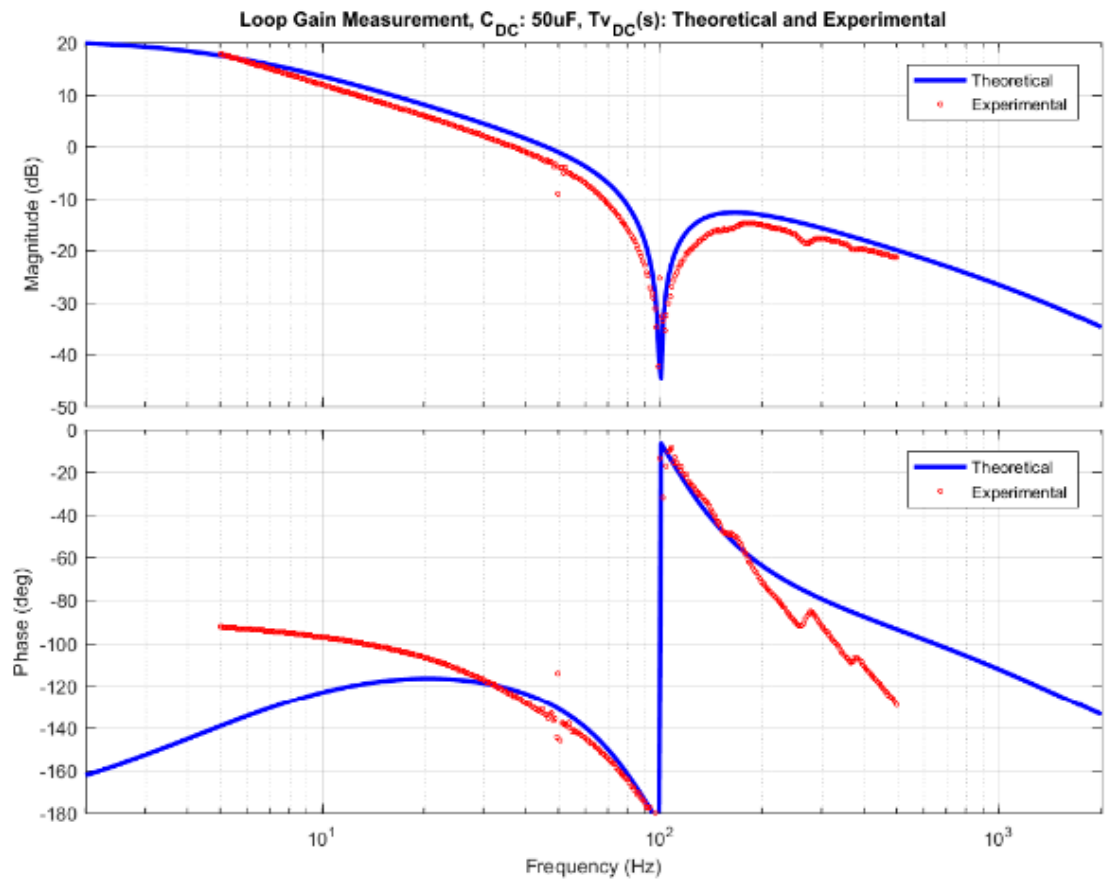

Figure 16. Loop gain frequency response of $\operatorname{Tv}_{D C}(s) . P_{G}=230 \mathrm{~W}, C_{D C}=50 \mu F$. Blue: theoretical, red: experimental.

\subsubsection{Start-up Time to Reach the MPP}

Figure 17 shows the evolution of the operation point at the PV source $\left(V_{\mathrm{PV}}, \mathrm{I}_{\mathrm{PV}}\right.$ and $\left.\mathrm{P}_{\mathrm{PV}}\right)$ from the start-up until the MPP was reached. The conventional implementation was faster $(2.75 \mathrm{~s})$ than the sensorless (12.6 s) due to the differences in the perturbation step, but once the MPP is achieved, both implementations continue at the MPP. 
Conventional MPPT start-up

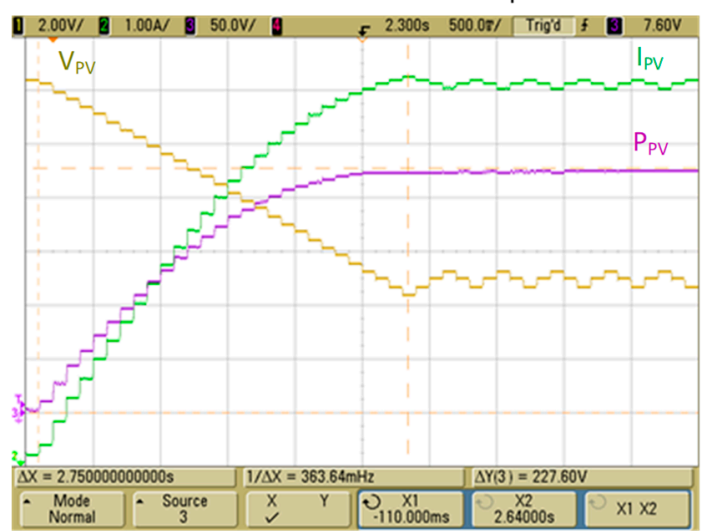

(a)

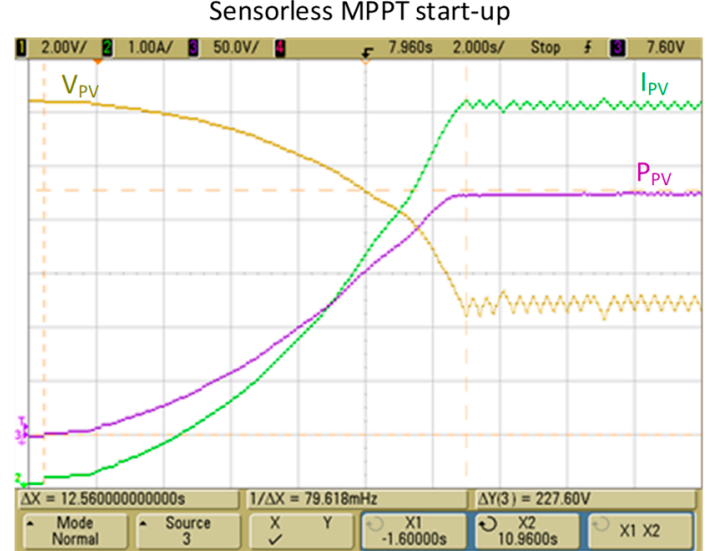

(b)

Figure 17. MPPT response from the start-up until the MPP is reached. $\mathrm{F}_{\mathrm{MPPT}}$ : $10 \mathrm{~Hz}$. (a): Conventional, $V_{\text {PV }}$ step: $\Delta V_{\text {PV_Ref }}=300 \mathrm{mV}$. (b): Sensorless, PCC Vc step: $\Delta V_{c}=12.5 \mathrm{mV}(\approx 250 \mathrm{~mA}$ close to the MPP).

\subsubsection{MPPT Performance Close to the MPP}

A key factor in the MPPT performance is the accuracy of the PV estimation and the dispersion of the operation point from the MPP along the I-V curve. The results shown in Figure 18 were obtained tracking the MPP of the $230 \mathrm{~W}$ PV panel at constant irradiation of $1000 \mathrm{~W} / \mathrm{m}^{2}$ during $50 \mathrm{~s}$. The results in Figure 18a correspond to the conventional MPPT algorithm and the results in Figure $18 \mathrm{~b}$ correspond to the sensorless algorithm. In both implementations, the operation points are very close to the MPP. The power extracted from the PV panel during the tests is shown in Table 4. In order to calculate the MPP tracking performance, the quotient between the average power and the peak power measured in each experiment has been used as a reference, as it is expressed by Equation (18). Although the sensorless algorithm presents a very slight disadvantage $(0.06 \%)$ in terms of the tracking efficiency, the performance of both methods is almost the same.

$$
\text { Tracking efficiency }=\frac{\text { Average Power }}{\text { Peak Power }} .
$$

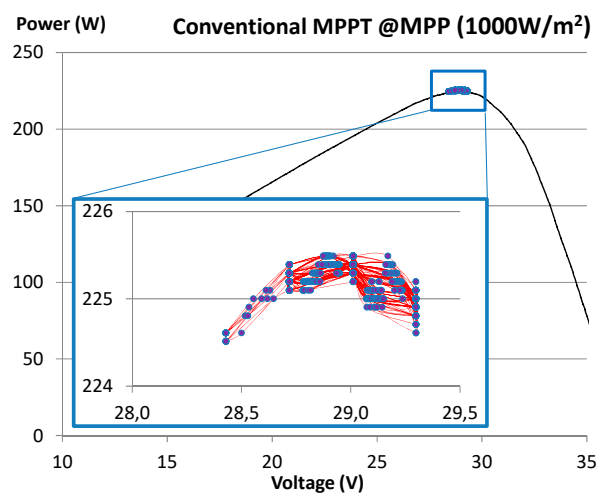

(a)

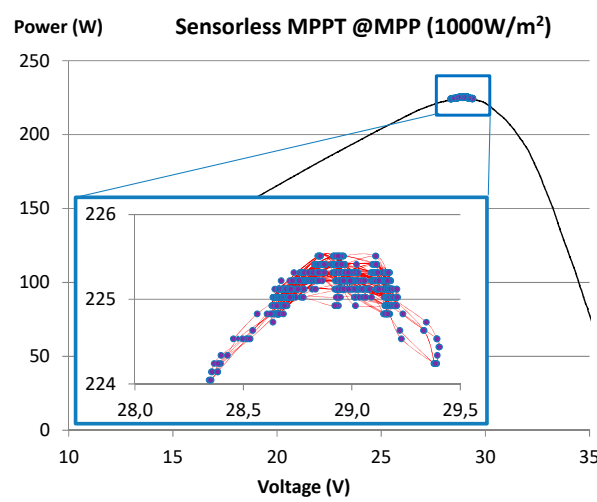

(b)

Figure 18. Dispersion of the operation point near the MPP. Total test time: $50 \mathrm{~s}$. $\mathrm{F}_{\mathrm{MPPT}}=10 \mathrm{~Hz}$. (a):

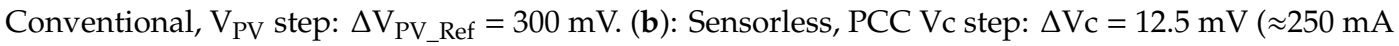
near the MPP). 
Table 4. Performance of the MPPT algorithms at the MPP under constant irradiation $\left(1000 \mathrm{~W} / \mathrm{m}^{2}\right)$.

\begin{tabular}{ccc}
\hline MPPT Implementation & Conventional & Sensorless \\
\hline Average power $(\mathrm{W})$ & 225.30 & 224.80 \\
Peak power $(\mathrm{W})$ & 225.49 & 225.11 \\
Tracking efficiency (\%) & 99.92 & 99.86 \\
\hline
\end{tabular}

The tracking of the MPP under heavy irradiation transients is shown in Figure 19. The tests have been performed for $50 \mathrm{~s}$ following the stages shown in Table 5. The black traces are the IV curve of the PV panel at $1000 \mathrm{~W} / \mathrm{m}^{2}$ and $600 \mathrm{~W} / \mathrm{m}^{2}$. The blue traces represent the evolution in stage 2 , during the reduction of the irradiation, and the red trace represents the evolution in stage 4 , during the increase of irradiation.

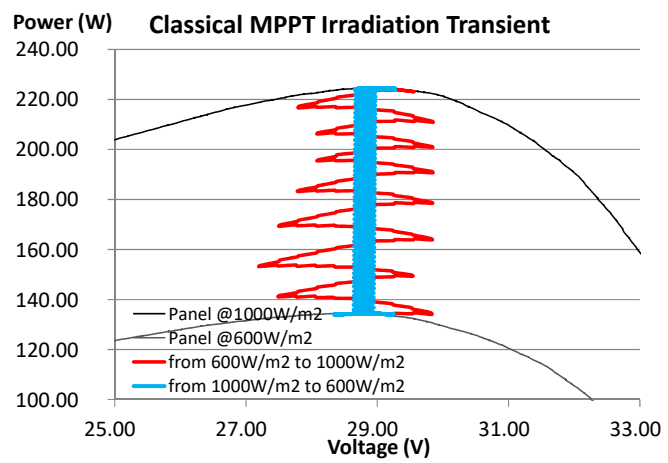

(a)

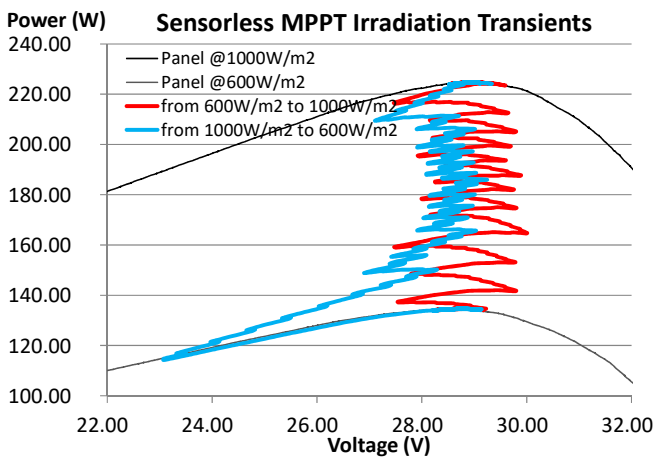

(b)

Figure 19. Irradiation transients test. Total time: $50 \mathrm{~s} . \mathrm{F}_{\mathrm{MPPT}}=10 \mathrm{~Hz}$. (a) Conventional, $\mathrm{V}_{\mathrm{PV}}$ step: $\Delta \mathrm{V}_{\mathrm{PV} \_ \text {Re }}=300 \mathrm{mV}$. (b) Sensorless, PCC Vc step: $\Delta \mathrm{Vc}=12.5 \mathrm{mV}(\approx 250 \mathrm{~mA}$ near the MPP $)$.

Table 5. Stages of the transient radiation test.

\begin{tabular}{ccc}
\hline Stage & Irradiation Profile & Duration \\
\hline 1 & Constant at $1000 \mathrm{~W} / \mathrm{m}^{2}$ & $10 \mathrm{~s}$ \\
2 & Linear decrease from $1000 \mathrm{~W} / \mathrm{m}^{2}$ to $600 \mathrm{~W} / \mathrm{m}^{2}$ & $10 \mathrm{~s}$ \\
3 & Constant at $600 \mathrm{~W} / \mathrm{m}^{2}$ & $10 \mathrm{~s}$ \\
4 & Linear increase from $600 \mathrm{~W} / \mathrm{m}^{2}$ to $1000 \mathrm{~W} / \mathrm{m}^{2}$ & $10 \mathrm{~s}$ \\
5 & Constant at $1000 \mathrm{~W} / \mathrm{m}^{2}$ & $10 \mathrm{~s}$ \\
\hline Total & - & $50 \mathrm{~s}$ \\
\hline
\end{tabular}

The power extracted from the PV panel during the tests is shown in Table 6. During stages 1, 3 and 5, both MPPTs tracked the MPP as was expected from the results shown in Table 4. During stage 2, the sensorless MPPT was not as accurate as the conventional one, but during stage 4 the sensorless MPPT exhibited a smaller dispersion of the operation point and, thus, a higher accuracy than the conventional one. It can be stated that the MPPT performance of both MPPTs was highly similar. Although the conventional MPPT had a faster start-up and was slightly more accurate in some tests, the performance of the proposed sensorless MPPT near the MPP was almost equal to the conventional implementation, but at a lower cost. 
Table 6. Transient radiation test results.

\begin{tabular}{cccc}
\hline Stage & Conventional MPPT & Sensorless MPPT & \% \\
\hline 1 & $225.30 \mathrm{~W}$ & $224.80 \mathrm{~W}$ & 0.998 \\
2 & $181.27 \mathrm{~W}$ & $173.51 \mathrm{~W}$ & 0.957 \\
3 & $134.90 \mathrm{~W}$ & $134.41 \mathrm{~W}$ & 0.996 \\
4 & $180.82 \mathrm{~W}$ & $180.36 \mathrm{~W}$ & 0.997 \\
5 & $225.30 \mathrm{~W}$ & $224.80 \mathrm{~W}$ & 0.998 \\
\hline Average & $189.52 \mathrm{~W}$ & $187.58 \mathrm{~W}$ & 0.989 \\
\hline
\end{tabular}

\section{Conclusions}

This paper focused on control techniques which help to reduce the cost of two-stage grid-connected $\mathrm{PV}$ inverters. In previous works, sensorless algorithms and techniques to reduce the capacitance of the DC-link have been proposed separately. The present study attempts to integrate both trends in a single implementation. The reduction of the DC-link capacitance requires a faster control loop to keep the DC-link voltage within safe values. However, this practice usually increases the THD of the current injected into the grid. The DC-link can be reduced in a factor of ten compared to standard values of the DC-link capacitance, yet with good values of the THDi, by increasing the speed of the voltage control loop and using a frequency adaptive notch filter tuned at twice the grid frequency.

SOGI structures are an effective way to implement tuned filters both in the inverter voltage loop and in its current loop. It is shown that the crossover frequency of the DC-link voltage control loop can be increased from typical values of $10 \mathrm{~Hz}$ to a value around $50 \mathrm{~Hz}$, yet getting a THDi value lower than $1 \%$. The combination of a fast voltage loop with a SOGI notch filter allows the reduction of the DC-link capacitance. An FLL-SOGI is used to get the value of the grid frequency to tune the SOGI controllers in the inverter control loops.

Summing up, this study proposes the implementation of the MPPT with no sensors at the PV source side, which takes advantages of the SOGI based enhancements implemented in the control of the converter. The high dynamics achieved by the inverter controllers yield a performance of the sensorless MPPT very similar to that of conventional MPPT implementations, but at a lower cost.

Author Contributions: R.G.-M., G.G. and E.F. proposed the main idea, performed the investigation and designed the experiments; R.G.-M. and G.G. developed the software, performed the experiments, and wrote the paper. M.L. and S.M. processed the data from the experimental results and reviewed the paper. G.G. and E.F. lead the project, acquired the funds for research.

Funding: This work has been co-financed by the Spanish Ministry of Economy and Competitiveness (MINECO) and by the European Regional Development Fund (ERDF) under Grant ENE2015-64087-C2-2-R and by the Spanish Ministry of Science, Innovation and University (MICINN) and the European Regional Development Fund (ERDF) under Grant RTI2018-100732-B-C21. The European Regional Development Fund (ERDF) and the Generalitat Valenciana (GVA) financed the purchase of the Cinergia GE\&EL 50 grid emulator and electronic load used during the experimental part of this work under Grant IDIFEDER/2018/036.

Conflicts of Interest: The authors declare no conflict of interest. The funders had no role in the design of the study; in the collection, analyses, or interpretation of data; in the writing of the manuscript, or in the decision to publish the results.

\section{Appendix A}

Table A1 shows the approximated costs of the prototype built for this study at the present time. It is important to note that a $6 \%$ cost saving is estimated. 
Table A1. Approximate costs of the prototype.

\begin{tabular}{cccc}
\hline Implementation & Conventional & \multicolumn{2}{c}{ Sensorless and Reduced DC-link } \\
\hline PCB & $100 €$ & $100 €$ & $100 €$ \\
\hline Common components & $400 €$ & $400 €$ & $400 €$ \\
\hline DC-link & Electrolytic $500 \mu \mathrm{F}$ & Electrolytic $50 \mu \mathrm{F}$ & Film $50 \mu \mathrm{F}$ \\
& $12 €$ & $5 €$ & $7 €$ \\
\hline $\mathrm{V}_{\mathrm{PV}}$ and IPV sensors & $25 €$ & $0 €$ & $0 €$ \\
\hline Total & $537 €$ & $505 €(94 \%)$ & $507 €(94.4 \%)$ \\
\hline
\end{tabular}

\section{References}

1. International Electrotechnical Commission. Electromagnetic Compatibility (EMC)—Part 3-2: Limits—Limits for Harmonic Current Emissions (Equipment Input Current $\leq 16$ A Per Phase); International Electrotechnical Commission (IEC): Geneva, Switzerland, 2018.

2. International Electrotechnical Commission. Electromagnetic Compatibility (EMC)—Part 3-4: Limits—Limitation of Emission of Harmonic Currents in Low-Voltage Power Supply Systems for Equipment with Rated Current Greater than 16 A; International Electrotechnical Commission (IEC): Geneva, Switzerland, 1998.

3. International Electrotechnical Commission. Electromagnetic compatibility (EMC)—Part 3-12: Limits_Limits for Harmonic Currents Produced by Equipment Connected to Public Low-Voltage Systems with Input Current $>16$ A and $\leq 75$ A Per Phase; International Electrotechnical Commission (IEC): Geneva, Switzerland, 2011.

4. Langella, R.; Testa, A.; Alii, E. IEEE Std 519-2014-IEEE Recommended Practice and Requirements for Harmonic Control in Electric Power Systems. IEEE Trans. Ind. Appl. 1989, 25, 6-7.

5. Espi, J.M.; Castello, J. A Novel Fast MPPT Strategy for High Efficiency PV Battery Chargers. Energies 2019, 12, 1152. [CrossRef]

6. Ahmed, J.; Salam, Z. A Modified P\&O Maximum Power Point Tracking Method With Reduced Steady-State Oscillation and Improved Tracking Efficiency. IEEE Trans. Sustain. Energy 2016, 7, 1506-1515.

7. Sher, H.A.; Rizvi, A.A.; Addoweesh, K.E.; Al-Haddad, K. A Single-Stage Stand-Alone Photovoltaic Energy System With High Tracking Efficiency. IEEE Trans. Sustain. Energy 2017, 8, 755-762. [CrossRef]

8. Liivik, E.; Chub, A.; Kosenko, R.; Vinnikov, D. Low-cost photovoltaic microinverter with ultra-wide MPPT voltage range. In Proceedings of the 2017 6th International Conference on Clean Electrical Power (ICCEP), Santa Margherita Ligure, Italy, 27-29 June 2017; pp. 46-52. [CrossRef]

9. Sher, H.A.; Addoweesh, K.E.; Haddad, K.A. An Efficient and Cost-Effective Hybrid MPPT Method for a Photovoltaic Flyback Micro-Inverter. IEEE Trans. Sustain. Energy 2017, 9, 1137-1144. [CrossRef]

10. Samrat, P.S.; Edwin, F.F.; Xiao, W. Review of current sensorless maximum power point tracking technologies for photovoltaic power systems. In Proceedings of the 2013 International Conference on Renewable Energy Research and Applications (ICRERA), Madrid, Spain, 20-23 October 2013; pp. 20-23. [CrossRef]

11. Kitano, T.; Matsui, M.; Xu, D.-H. Power sensor-less MPPT control scheme utilizing power balance at DC link-system design to ensure stability and response. In Proceedings of the IECON 01-27th Annual Conference of the IEEE Industrial Electronics Society, Denver, CO, USA, 29 November-2 December 2001; Volume 2, pp. 1309-1314.

12. Choi, B.-Y.; Jang, J.-W.; Kim, Y.-H.; Ji, Y.-H.; Jung, Y.-C.; Won, C.-Y. Current sensorless MPPT using photovoltaic AC module-type flyback inverter. In Proceedings of the 2013 IEEE International Symposium on Industrial Electronics (ISIE), Taipei, Taiwan, 28-31 May 2013; pp. 28-31. [CrossRef]

13. Metry, M.; Shadmand, M.B.; Balog, R.S.; Abu-Rub, H. MPPT of Photovoltaic Systems Using Sensorless Current-Based Model Predictive Control. IEEE Trans. Ind. Appl. 2017, 53, 1157-1167. [CrossRef]

14. Femia, N.; Petrone, G.; Spagnuolo, G.; Vitelli, M. A Technique for Improving P\&O MPPT Performances of Double-Stage Grid-Connected Photovoltaic Systems. IEEE Trans. Ind. Electron. 2009, 56, 4473-4482. [CrossRef]

15. Garcerá, G.; González-Medina, R.; Figueres, E.; Sandia, J. Dynamic modeling of DC-DC converters with peak current control in double-stage photovoltaic grid-connected inverters. Int.J. Circuit Theory Appl. 2012, 40, 793-813. [CrossRef] 
16. Zhu, G.; Ruan, X.; Zhang, L.; Wang, X. On the Reduction of Second Harmonic Current and Improvement of Dynamic Response for Two-Stage Single-Phase Inverter. IEEE Trans. Power Electron. 2015, 30, 1028-1041. [CrossRef]

17. Karanayil, B.; Agelidis, V.G.; Pou, J. Performance Evaluation of Three-Phase Grid-Connected Photovoltaic Inverters Using Electrolytic or Polypropylene Film Capacitors. IEEE Trans. Sustain. Energy 2014, 5, 1297-1306. [CrossRef]

18. Schonberger, J. A single phase multi-string PV inverter with minimal bus capacitance. In Proceedings of the 2009 13th European Conference on Power Electronics and Applications, Barcelona, Spain, 8-10 September 2009; pp. 1-10. [CrossRef]

19. Messo, T.; Jokipii, J.; Suntio, T. Minimum DC-link capacitance requirement of a two-stage photovoltaic inverter. In Proceedings of the 2013 IEEE Energy Conversion Congress and Exposition, Denver, CO, USA, 15-19 September 2013; pp. 999-1006. [CrossRef]

20. Heo, J.; Matsuo, K.; Hen, P.; Kondo, K. Dynamics of a minimum DC link voltage driving method to reduce system loss for hybrid electric vehicles. In Proceedings of the 2017 IEEE International Electric Machines and Drives Conference (IEMDC), Miami, FL, USA, 21-24 May 2017; pp. 1-7.

21. Karanayil, B.; Agelidis, V.G.; Pou, J. Evaluation of DC-link decoupling using electrolytic or polypropylene film capacitors in three-phase grid-connected photovoltaic inverters. In Proceedings of the IECON 2013-39th Annual Conference of the IEEE Industrial Electronics Society, Vienna, Austria, 10-13 November 2013; pp. 6980-6986. [CrossRef]

22. Bazargan, D.; Bahrani, B.; Filizadeh, S. Reduced Capacitance Battery Storage DC-link Voltage Regulation and Dynamic Improvement Using a Feedforward Control Strategy. IEEE Trans. Energy Convers. 2018, 33, 1659-1668. [CrossRef]

23. Ciobotaru, M.; Teodorescu, R.; Blaabjerg, F. A New Single-Phase PLL Structure Based on Second Order Generalized Integrator. In Proceedings of the 2006 37th IEEE Power Electronics Specialists Conference, Jeju, Korea, 18-22 June 2006; pp. 1-6. [CrossRef]

24. Rodriguez, P.; Luna, A.; Ciobotaru, M.; Teodorescu, R.; Blaabjerg, F. Advanced Grid Synchronization System for Power Converters under Unbalanced and Distorted Operating Conditions. In Proceedings of the IECON 2006-32nd Annual Conference on IEEE Industrial Electronics, Paris, France, 7-10 November 2006; pp. 5173-5178. [CrossRef]

25. Rodriguez, P.; Luna, A.; Candela, I.; Teodorescu, R.; Blaabjerg, F. Grid synchronization of power converters using multiple second order generalized integrators. In Proceedings of the 2008 34th Annual Conference of IEEE Industrial Electronics, Orlando, FL, USA, 10-13 November 2008; pp. 755-760. [CrossRef]

26. Rodriguez, P.; Luna, A.; Etxeberria, I.; Hermoso, J.R.; Teodorescu, R. Multiple second order generalized integrators for harmonic synchronization of power converters. In Proceedings of the 2009 IEEE Energy Conversion Congress and Exposition, 2009 ECCE, San Jose, CA, USA, 20-24 September 2009; pp. 2239-2246. [CrossRef]

27. Rodríguez, P.; Luna, A.; Candela, I.; Mujal, R.; Teodorescu, R.; Blaabjerg, F. Multiresonant Frequency-Locked Loop for Grid Synchronization of Power Converters Under Distorted Grid Conditions. IEEE Trans. Ind. Electron. 2011, 58, 127-138. [CrossRef]

28. Liserre, M.; Blaabjerg, F.; Hansen, S. Design and control of an LCL-filter-based three-phase active rectifier. IEEE Trans. Ind. Electron. 2009, 56, 4492-4501. [CrossRef]

29. TMS320F28335 Delfino ${ }^{\mathrm{TM}}$ 32-bit MCU with 150 MIPS, FPU, 512 KB Flash, EMIF, 12b ADC. Available online: http://www.ti.com/product/TMS320F28335 (accessed on 1 May 2019).

30. Castilla, M.; Miret, J.; Matas, J.; Garcia de Vicuna, L.; Guerrero, J.M. Control Design Guidelines for Single-Phase Grid-Connected Photovoltaic Inverters With Damped Resonant Harmonic Compensators. IEEE Trans. Ind. Electron. 2009, 56, 4492-4501. [CrossRef]

31. Ciobotaru, M.; Teodorescu, R.; Blaabjerg, F. Control of single-stage single-phase PV inverter. In Proceedings of the 2005 European Conference on Power Electronics and Applications, Dresden, Germany, 11-14 September 2005; pp. 20-26. [CrossRef]

32. Teodorescu, R.; Blaabjerg, F.; Borup, U.; Liserre, M. A new control structure for grid-connected LCL PV inverters with zero steady-state error and selective harmonic compensation. In Proceedings of the Nineteenth Annual IEEE Applied Power Electronics Conference and Exposition, Anaheim, CA, USA, 22-26 February 2004; Volume 1, pp. 580-586. [CrossRef] 
33. Reza, M.S.; Ciobotaru, M.; Agelidis, V.G. Grid voltage offset and harmonics rejection using second order generalized integrator and kalman filter technique. In Proceedings of the 20127 th International Power Electronics and Motion Control Conference (IPEMC), Harbin, China, 2-5 June 2012; pp. 104-111. [CrossRef]

34. Timbus, A.V.; Ciobotaru, M.; Teodorescu, R.; Blaabjerg, F. Adaptive resonant controller for grid-connected converters in distributed power generation systems. In Proceedings of the Twenty-First Annual IEEE Applied Power Electronics Conference and Exposition, Dallas, TX, USA, 19-23 March 2006. [CrossRef]

35. Teodorescu, R.; Liserre, M.; Rodriguez, P. Chapter 9: Grid Converter Control for WTS. In Grid Converters for Photovoltaic and Wind Power Systems; Wiley-IEEE Press: Chichester, England, 2010; pp. 205-235. ISBN 978-0-470-05751-3.

36. Hohm, D.P.; Ropp, M.E. Comparative study of maximum power point tracking algorithms. Prog. Photovolt. Res. Appl. 2003, 11, 47-62. [CrossRef]

37. International Standard IEC 61000-4-7. Electromagnetic Compatibility (EMC)_Part 4-7:Testing and Measurement Techniques-General Guide on Harmonics and Interharmonics Measurements and Instrumentation, for Power Supply Systems and Equipment Connected Thereto; International Electrotechnical Commission (IEC): Geneva, Switzerland, 2002.

38. Middlebrook, R.D. Measurement of Loop Gain in Feedback Systems. Int. J. Electron. 1975, 38, 485-512. [CrossRef]

39. Gonzalez-Espin, F.; Figueres, E.; Garcera, G.; Gonzalez-Medina, R.; Pascual, M. Measurement of the Loop Gain Frequency Response of Digitally Controlled Power Converters. IEEE Trans. Ind. Electron. 2010, 57, 2785-2796. [CrossRef]

40. Gonzalez-Espin, F.; Figueres, E.; Garcera, G.; Gonzalez, R.; Carranza, O.; Gonzalez, L.G. A digital technique to measure the loop gain of power converters. In Proceedings of the 13th European Conference on Power Electronics and Applications, Barcelona, Spain, 8-10 September 2009; pp. 1-10.

(C) 2019 by the authors. Licensee MDPI, Basel, Switzerland. This article is an open access article distributed under the terms and conditions of the Creative Commons Attribution (CC BY) license (http://creativecommons.org/licenses/by/4.0/). 